\title{
Experimental Study of the Interaction between Recrystallization and Precipitation Processes of an AA8011 Commercial Alloy
}

\author{
Ney José Luiggi, ${ }^{1}$ María Valera, ${ }^{1}$ Jesús P. Rodriguez, ${ }^{2}$ and José Prin ${ }^{3}$ \\ ${ }^{1}$ Grupo Física de Metales, Departamento de Física, Núcleo de Sucre, Universidad de Oriente, Cumaná 6101, Venezuela \\ ${ }^{2}$ IDECYT, Universidad Simón Rodríguez, Caracas 1060, Venezuela \\ ${ }^{3}$ Instituto de Investigaciones de Biomedicina y Ciencias Aplicadas (IIBCA), Universidad de Oriente, Cumaná 6101, Venezuela \\ Correspondence should be addressed to Ney José Luiggi; nluiggi51@gmail.com
}

Received 16 July 2013; Revised 4 December 2013; Accepted 6 December 2013; Published 22 January 2014

Academic Editor: B. S. Murty

Copyright (C) 2014 Ney José Luiggi et al. This is an open access article distributed under the Creative Commons Attribution License, which permits unrestricted use, distribution, and reproduction in any medium, provided the original work is properly cited.

\begin{abstract}
Phase changes in a commercial AA8011 alloy from different initial microstructure conditions were studied using thermoelectric power $(\Delta S)$, differential scanning calorimetry (DSC), and transmission electron microscopy (TEM) techniques with the purpose of obtaining evidence of the interaction between recovery-precipitation and recrystallization-precipitation processes occurring during nonisothermal heating at different rates. Thermoelectric power and its thermal derivative reflect this evidence by a displacement of the characteristic precipitation peaks, the recovery and recrystallization contributions remaining masked by the strong incidence of the iron precipitation on that property, while DSC measurements detect the emergence of new peaks not observed on thermograms of homogenized samples. An exhaustive study of these peaks permits direct differentiation between precipitation and recoveryrecrystallization contributions. TEM confirms the interaction between both processes by means of local observations.
\end{abstract}

\section{Introduction}

The study of the interaction that occurs between phase precipitation process and recrystallization in deformed materials is a topic of great interest in materials science because this interaction regulates the kinetics of growth of new grains and the formation of phases in the material. The combination of both effects certainly leads to modifications of the physical and mechanical properties of the material.

A plastically deformed material shows a great amount of internal strains, mainly as dislocations, which store part of the energy transferred to the crystal during deformation, the reordering of which helps release said energy. Many mechanisms contribute to that end, where the recovery and recrystallization processes recover and lead to the appearance of new grains through the release of stored energy, the evolution of the recrystallization occurring in a collective manner by nucleation and growth [1-6].
The diffusive process conducive to the phase transformation also takes place at the same temperature ranges where recrystallization occurs, both processes being regulated by the starting microstructure.

Schematically, both a possible evolution of the atomic supersaturation after quenching of a homogenized sample as a function of aging time at a temperature below the solubility limit and the evolution of the density of internal strain as a function of the degree of deformation by rolling in homogenized and quenched samples are shown in Figure 1. Immediately after quenching at a temperature below the solubility limit, the homogenized sample shows the highest atomic supersaturation (signaled with 1 in the figure). As the sample is aged, the atomic supersaturation decreases down to a fully aged sample with the lowest atomic supersaturation (marked with 3). The other curve in Figure 1 shows how the strain concentration increases when a mechanical work is applied. Number 4 corresponds to a sample without deformation, 


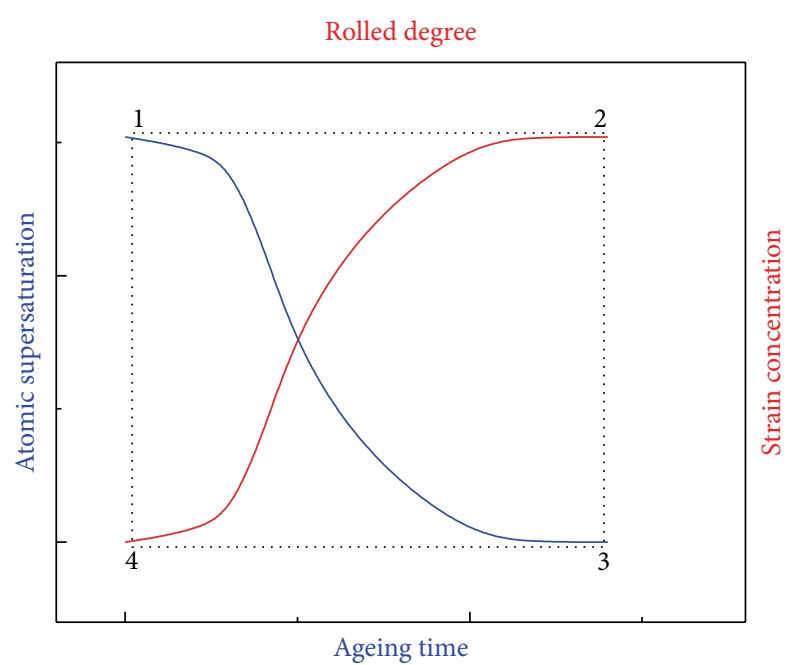

FIGURE 1: Schematic representation of the atomic supersaturation versus aging time and strain concentration versus degree of rolling for homogenized and quenched samples.

while number 2 corresponds to a highly deformed sample, where the density of strains is at a maximum. The four dotted straight lines that intercept both curves represent the extreme conditions of supersaturation and deformation that the initial microstructure of the sample can hypothetically undergo. We may infer from that diagram that, for certain initial microstructural conditions, a simultaneous participation of both processes will ensue. Generally, in the literature, both effects are not separated; in such cases, the results must correspond to one single mechanism and not to the particular mechanisms involved.

The aim of this work is to confirm this interaction by using different techniques and starting microstructures. The commercial alloy AA8011 was chosen for this purpose, where $\mathrm{Fe}$ and $\mathrm{Si}$, as main alloying elements, regulate the microstructure and properties of the Al-Fe-Si system. Several works dealing with this alloy have been reported in the literature [7-11]. Garcia-Cordovilla and Louis [12] differentiated exothermal reactions associated with precipitation and recrystallization of this alloy via DSC measurements.

This paper complements the communication reported in work [13] on Al-Fe-Si alloy rolled samples, now considering different starting microstructures achieved by rolling and aging at specific temperatures, whereby the samples studied are characterized, aside from DSC and $\Delta S$, by TEM in order to relate the changes detected in the microstructure of homogenized, deformed, and annealed samples to the mechanisms responsible for the recovery-recrystallization and precipitation processes. The derivative of the thermoelectric power is introduced as a complementary way to identify peaks associated with the particular reactions.

The paper is organized as follows. Section 2 presents the methodology used and defines samples and heat treatments. Section 3 outlines details theoretically associated with each technique employed, and Section 4 presents the results and discussion.

\section{Methodology}

2.1. Samples Analyzed. Our work was done on commercial as-cast samples of the AA8011 alloy supplied by C.V.G ALCASA of Venezuela in $6 \mathrm{~mm}$ thick rolls, milled to $0.5 \mathrm{~mm}$, the composition of which is given in Table 1.

2.2. Thermal Treatments and Equipment. In order to have different starting microstructures, the samples were subjected to different thermal treatments.

(1) Samples were subjected to homogenization for six hours at $620^{\circ} \mathrm{C}$, then cooled in aqueous solution kept at $20^{\circ} \mathrm{C}$. This treatment guarantees that the starting microstructure will have a high supersaturation of atoms in solid solution and a low concentration of internal stresses. The samples are designated as HS.

(2) Samples were subjected to treatment 1, then annealed to different temperatures in order to guarantee a controlled supersaturation of the solute and a low concentration of internal stresses. The samples are designated as AHS.

(3) Samples were subjected to treatment 1, then deformed by quenching via twin-roll casting to different reductions in thickness. The starting microstructure will display high atom supersaturation and a concentration of internal stresses that increases with the deformation rate. The samples are designated as DHS.

(4) Samples under condition 3 are subjected to artificial annealing for specific amounts of time at different temperatures. This treatment tries to regulate supersaturation of the solute and the concentration of internal stresses of treatment 2 . The samples are designated as ADHS.

Thermoelectric power variations measurements were estimated by the Seebeck coefficient in equipment with a $\pm 0.002 \mu \mathrm{V} / \mathrm{K}$ accuracy [14], whereas DSC measurements were made with a NETZSCH JUPITER STA $499 \mathrm{C}$, the sensitivity of which allows for the detection of very-lowenthalpy transitions. In both cases, high purity aluminum was used as reference and baseline. Electron microscopy studies were made at IIBCA-UDO-VENEZUELA with a $100 \mathrm{kV}$ HITACHI H600 transmission electron microscope.

\section{Fundamental Aspects of the Experimental Techniques Used}

In order to benefit from the interpretation of our measurements, we need to consider the basic concepts related to each technique.

3.1. Thermoelectric Power. Our measuring equipment is based on the thermoelectric effect known as the Seebeck effect $[15,16]$ that measures the variation in thermoelectric potential within a temperature gradient. The potential is generated because of both the distinct electronic distribution on each side of the sample as a result of the heat gradient 
TABLE 1: Chemical composition of the AA8011 alloy.

\begin{tabular}{lcccccc}
\hline $\mathrm{Al}$ & $\mathrm{Fe}$ & $\mathrm{Si}$ & $\mathrm{Mn}$ & $\mathrm{Zn}$ & $\mathrm{Cr}$ & $\mathrm{Cu}$ \\
\hline Rem (weight \% ) & 0.56 & 0.40 & 0.01 & 0.004 & 0.003 & 0.01 \\
Rem (At.\% ) & 0.271 & 0.385 & 0.00493 & 0.00166 & 0.00156 & 0.00426 \\
\hline
\end{tabular}

and the chemical potential difference introduced by the union of two different materials (samples and conducting wiring). Three basic relationships allow us to coherently formulate a satisfactory assessment of $\Delta S$ [17].

(1) The Mott relation for diffusion thermoelectric power is

$$
S_{d}=\frac{\pi^{2} k_{b}^{2}}{3|e|}\left[\frac{1}{\rho} \frac{\partial \rho}{\partial E}\right]_{E=E_{F}}
$$

where $\rho$ is the resistivity of the sample, $E$ is the electronic energy of the sample, and subindex $F$ is used to specify the Fermi energy of the material being studied.

(2) The Matthiessen relation, particularly as applied to diluted alloys, is

$$
\rho=\rho_{0}+\sum_{i, o}\left(c_{i} \rho_{i}+c_{o} \rho_{o}\right)
$$

where subscripts $0, i$, and $o$ represent the contribution from the thermal vibrations or ideal contribution without matrix defect, the contribution from solute atoms in solid solution, and the contribution from atoms outside the solid solution, respectively. $c$ represents the atomic concentration and the values of $\rho_{i}$ and $\rho_{0}$ for different element of alloying in aluminum are given in [18].

(3) The Nordheim-Gother rule applied to the relative variation of diffusion thermoelectric power relative to the thermoelectric power of the ideal material is

$$
\Delta S_{d}=\frac{\sum \Delta \rho_{i} \Delta S_{i}}{\rho}
$$

where $\Delta S_{i}$ represents thermoelectric power specific to each element added to the aluminum matrix and $\Delta \rho_{i}$ is the resistivity variation generated by each alloying element in aluminum. Once the specific values of both the resistivity and the thermoelectric power of each alloying element are known, the measured value of the diffusion thermoelectric power for particular values of the atom concentrations given in (2) by $c_{i}$ and $c_{o}$ can be reproduced.

The literature shows that measurements of thermoelectric power [18] are sensitive to the concentration of the solute in the solid solution; hence, by using the theoretical base stated in [18], we can evaluate the contribution of each element of the alloy to thermoelectric power measured. The thermoelectric power sensitivity to the concentration of atoms in solid solution makes this technique a very useful tool to follow the processes of phase transformations under either isothermal or nonisothermal conditions. The thermoelectric power variation from one temperature to another induces changes in atomic concentration that blend with the structural transformation in such a way that the derivative of the thermoelectric power, as in other techniques, will show peaks and troughs characteristic of the different reactions; that is, the derivative of the thermoelectric power allows for direct observation of the kinetics of phase changes occurring during a specific thermal treatment. It is important for our analysis to indicate that the specific $\Delta S$ values [17] for $\mathrm{Fe}$ and $\mathrm{Si}$ are -8.00 and $-0.74 \mu \mathrm{V} / \mathrm{K}$ and that the specific $\Delta \rho$ values are 2.56 and $1.02 \mu \Omega \mathrm{cm} / \mathrm{wt} \%$, respectively. With these values, theoretical equations (3) and (4), the particular microstructural conditions, and the contributions of Fe and Si to the TEP can be evaluated.

3.2. Differential Scanning Calorimetry (DSC). DSC studies measure the difference in temperature or the thermal potential registered between the sample being studied and the reference sample, where said measurement is proportional to the heat flow $Q$ registered as a function of the time or temperature. The $Q$ variation is expressed as a function of the specific heat of sample $C_{P}$, its mass $m$, and the heating rate $\Phi=d T / d t$

$$
\frac{d Q}{d t}=m C_{P} \frac{d T}{d t}
$$

The area below the curve between two temperatures corresponds to the changes in the amount of heat of the sample:

$$
\Delta Q=\int_{T_{1}}^{T_{2}}\left(\frac{d Q}{d t}\right) d t
$$

Calorimetric measurements [19] are sensitive to both endothermic and exothermic reactions occurring during changes in microstructure, being therefore very useful in determining the kinetics of phase changes of materials. The heat flow measured and the reaction enthalpy are related to the extension of the conversion or transformed fraction, via numerical methods, allowing us to deduce the kinetic parameters associated with the reaction.

3.3. Transmission Electron Microscope. The evolution of the microstructure was directly observed with a transmission electron microscope. First, thin disks of 3 and $0.12 \mathrm{~mm}$ in diameter and thickness, respectively, were electropolished with the JET technique and then impacted in the center of both sides with an electrolyte stream to reduce thickness until an orifice was made. Thickness around the orifice was less than $0.5 \mu \mathrm{m}$, permitting the electron beam of the microscope to pass through. The amount of electrolytes used was $20 \%$ perchloric acid and $80 \%$ methanol. Micrographs were obtained with a HITACHI Transmission Electron Microscope, model H-600 (accelerating voltage of $100 \mathrm{kV}$ ). 


\section{Experimental Results}

\subsection{Thermoelectric Power and Derivatives}

4.1.1. Continuous and Isochronous Heating. Figure 2(a) shows thermoelectric power as a function of temperature for the AA8011 alloy subjected to different reductions in thickness via rolling during continuous heating at a rate of $2^{\circ} \mathrm{C} / \mathrm{min}$. The $\Delta S$ values taken immediately after rolling, reported in our previous work [13], increase as the rolling rate increases, which shows that the rolling process induces precipitation of the solute and impoverishes the solid solution, no doubt with the participation of a greater dislocation density as the deformation by rolling increases. Figure 2(a) shows a strong increase in $\Delta S$ up to $425^{\circ} \mathrm{C}$ for homogenized HS samples and up to $380^{\circ} \mathrm{C}$ for severely deformed samples ( $85 \%$ reduction in thickness), while, for intermediate deformations, the peak is orderly placed between those two temperatures. Afterwards, a decline slowly ensues in homogenized samples, the decrease being more pronounced on DHS as the rolling rate increases. A second peak is clearly shown in severely deformed samples at $460^{\circ} \mathrm{C}$, followed by a pronounced drop indicating that the atomic agglomerates enter into solid solution. Therefore, the increase of $\Delta S$ is associated with the precipitation process, whereas its decrease is associated with the dissolution of precipitates, the inflexion points of said curves representing the maximum transformation rate of the precipitation or dissolution processes, respectively. The derivative of $\Delta S$ with respect to temperature shows peaks and troughs for the temperature ranges where measurements of $\Delta S$ showed phase precipitation and dissolution, respectively; hence, in the $d \Delta S / d T$ versus $T$ curve, positive peaks completely represent the precipitation process, whereas the process $f$ dissolution of precipitates is represented by a trough, just as in DSC measurements of exothermic and endothermic reactions associated with those processes.

Figure 2(b) shows the derivative of $\Delta S$ with respect to temperature for the curves of Figure 2(a). An important reaction is seen for $\mathrm{MH}$ samples, the maximum of which is found at $375^{\circ} \mathrm{C}$, associated mainly with the precipitation of the $\alpha$-AlFeSi phase, albeit the presence of the $\Theta-\mathrm{AlCu}_{2}$ [3] has been detected in a much lesser proportion at that level, followed by both an endothermic reaction associated with a corresponding dilution and a new exothermic transformation of less magnitude around $470^{\circ} \mathrm{C}$, which corresponds mainly to the redistribution of $\mathrm{Fe}$ atoms and the generation of the equilibrium phase of the $\mathrm{Al}_{3} \mathrm{Fe}$ system. No other transformation seems to occur in the HS samples. The effect from rolling begins to be noticed even for a $25 \%$ reduction in sample thickness, where the $\alpha$-AlFeSi appears at $352^{\circ} \mathrm{C}$ as a consequence of the dislocation density introduced by rolling, the effect of which is to accelerate the precipitation of that phase. Said acceleration behavior of the precipitation is maintained as the rolling is increased close to a $75 \%$ reduction in thickness, where it appears that the number of dislocations introduced is such that said dislocations tend to rearrange themselves in a different manner, slowing the process of acceleration of precipitation of that phase to a temperature near $332^{\circ} \mathrm{C}$. This behavior is different in the precipitation of the

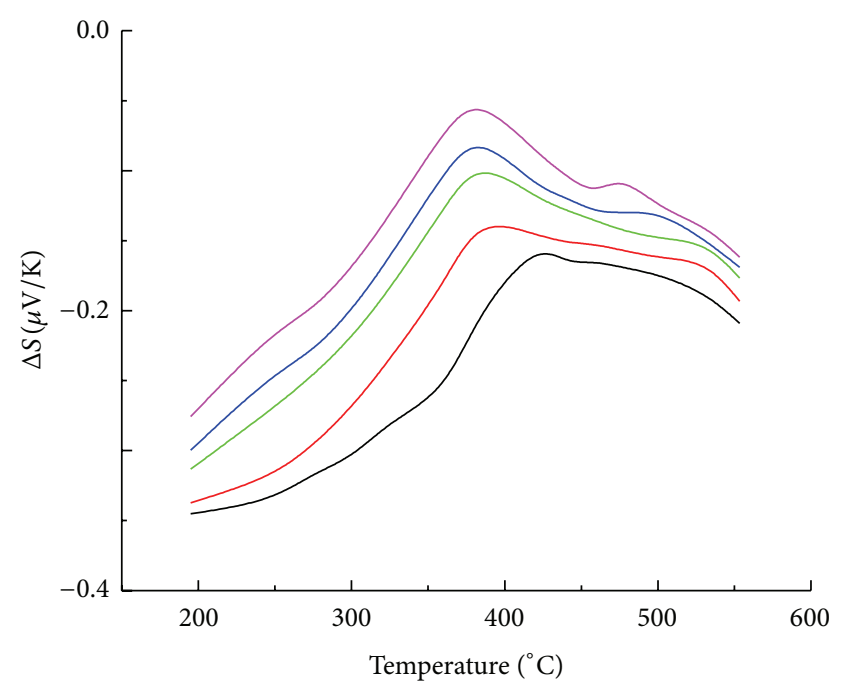

(a)

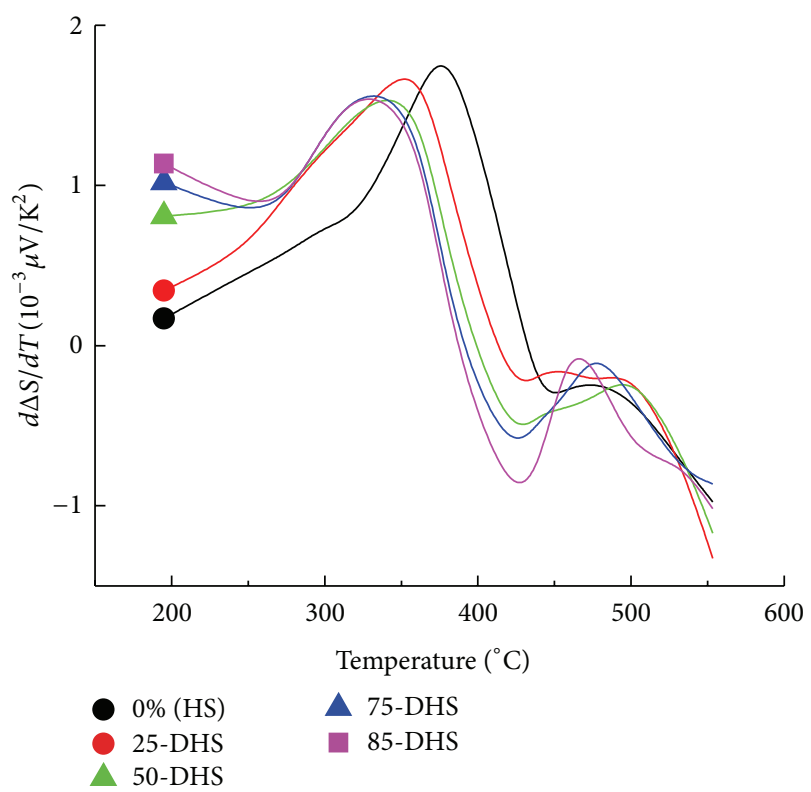

(b)

FIGURE 2: (a) Thermoelectric power and (b) derivative of the thermoelectric power versus temperature for the homogenized AA8011 alloy, quenched and deformed at different rolling degrees, then annealed continuously at $2^{\circ} \mathrm{C} / \mathrm{min}$.

$\mathrm{Al}_{3} \mathrm{Fe}$ phase, the precipitation of which seems to slow down with the increase of rolling to a $50 \%$ reduction in thickness, to later accelerate for severe deformations. It is also worth noting that, for severe deformations, an initial endothermic transformation occurs towards $250^{\circ} \mathrm{C}$, which is associated with the recovery process and the dissolution of the GuinierPreston zones. This behavior, not observed in HS samples, is typical of the DHS samples and makes us ponder whether the recovery process occurs under $250^{\circ} \mathrm{C}$, a process that increases according to the degree of rolling. Two processes coexist in the first exothermic reaction: the precipitation of the $\alpha$-AlFeSi phase and the recrystallization of grains from the release of 
energy absorbed during rolling. As for the equilibrium phase, the changes observed indicate an interaction between the precipitation of said phase and the final growth stage of grains. Note that above $500^{\circ} \mathrm{C}$ the qualitative behavior of all curves is similar, indicating that the recrystallization process has been completed.

Figure 3 shows the results of $\Delta S$ for samples subjected to isochronous heating for 10 minutes at each temperature. The intention behind such heating is to monitor the effect of each temperature on microstructure changes that occur in the HS and DHS samples studied. Figure 3(a) shows that for temperatures below the appearance of the first peak, the behavior observed is similar to the one shown previously, even though the position of said peak seems to be slightly changed due to the isochronous treatment of the samples. Like in the previous case for HS and DHS samples, the peak is associated with the precipitation of the $\alpha$-AlFeSi phase; however, the release of energy stored must occur simultaneously in the DHS samples, although not enough for a complete recrystallization to occur, the reason being that the measurements of thermoelectric power still keep showing a single peak associated with both processes, the precipitation of Fe masking the particular effect that the dislocations may have on that property $[9,13]$. However, at higher temperatures, the dissolution of the $\alpha$ phase, as well as the precipitation of the $\mathrm{Al}_{3} \mathrm{Fe}$ phase, seems to present a more uniform behavior in agreement with our previous explanation. Towards $486^{\circ} \mathrm{C}$, an important and uniform decrease in $\Delta S$ begins in the HS and DHS samples, indicating that the recrystallization process has been completed. Figure 3(b) shows the derivative $\Delta S$ as a function of temperature. The differences not detected in Figure 3(a) are detailed. The two exothermic transformations inherent to the precipitation of both the $\alpha$-AlFeSi and the $\mathrm{Al}_{3} \mathrm{Fe}$ phases are present, as well as the endothermic reactions that lead to the dissolution of the Guinier-Preston zones in the first inverted peak and to the redistribution of dislocations in severely deformed samples and, in the second peak, to the dissolution of the $\alpha$-AlFeSi phase. This figure highlights the effect of isochronous heating at high temperatures which tends, in every case, to uniform both the precipitation and the bringing of the $\mathrm{Al}_{3} \mathrm{Fe}$ equilibrium phase into solid solution. This happens, among other reasons, because 10 minutes at such temperatures is seemingly sufficient to complete the recrystallization process. It is important to note that while the precipitation peak of the $\alpha$ phase is placed at $383^{\circ} \mathrm{C}$, the joint peak of precipitation and recrystallization occurs between $330^{\circ} \mathrm{C}$ for $25 \%$ reduction in thickness and $314^{\circ} \mathrm{C}$ for $85 \%$ reduction in thickness, respectively, in total agreement with the value reported by Lima [10].

4.1.2. Isothermal Preaging at $300^{\circ} \mathrm{C}$ in Highly Rolled Samples $(85 \%)$. Preaging for different time periods at $300^{\circ} \mathrm{C}$ and measuring under isochronous 25 -minute heating conditions seek to decrease the amount of solute in the solid solution, so that a precipitation-recrystallization interaction different from that of the previous cases is promoted. The values of

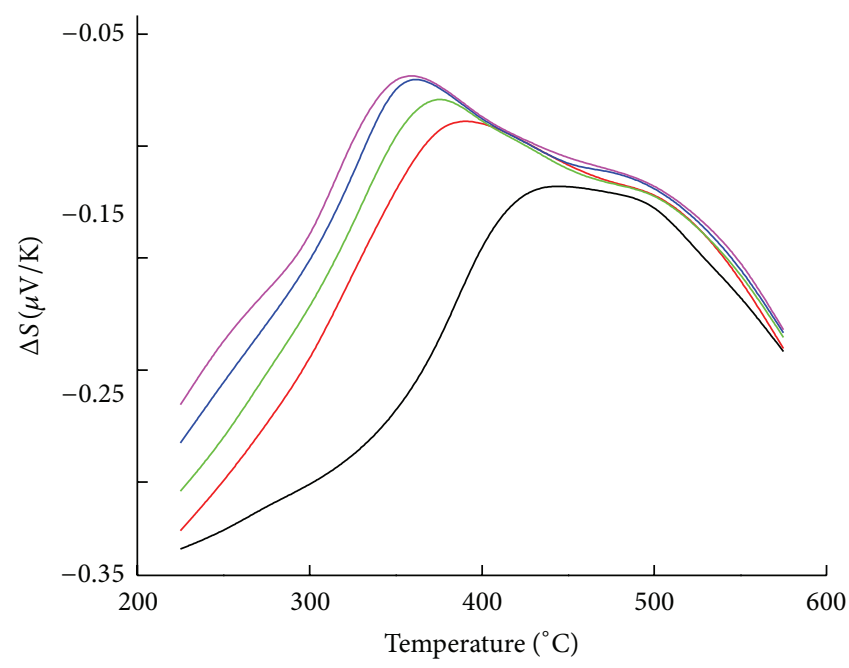

(a)

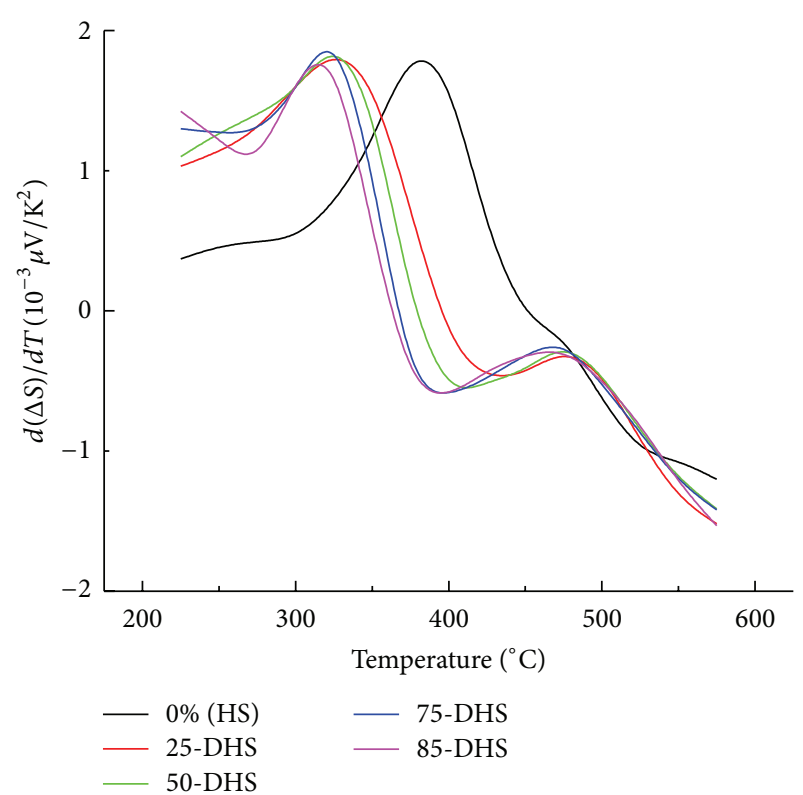

(b)

FIgURE 3: (a) Thermoelectric power and (b) derivative of the thermoelectric power versus temperature for the homogenized AA8011 alloy, quenched and deformed at different rolling degrees, then heated isochronously during 10 minutes at each temperature.

$\Delta S$, once the corresponding preaging of the samples has been done, and before the heating begins, are shown in Table 2. We can see how $\Delta S$ increases as the rolled sample stays at $300^{\circ} \mathrm{C}$ for a longer period of time, indicating a solute-impoverished aluminum matrix.

Figure 4(a) shows the evolution of $\Delta S$ as a function of temperature under the conditions mentioned above. We can observe how preaging affects the first stages of the curve, given that, for a longer time at $300^{\circ} \mathrm{C}$, a greater precipitation of $\mathrm{Fe}$ and $\mathrm{Si}$ is promoted, impoverishing the solid solution and recovering the microstructure by eliminating dislocations and defects introduced by rolling. 
Once the peak associated with both precipitation of the $\alpha$ phase and recrystallization has been reached, the combined effect of preaging and isochronous treatment tends to show a behavior similar to $\Delta S$ on each curve, meaning, in light of the treatment applied, that only before and during the precipitation of the $\alpha$-AlFeSi phase is there a strong interaction between the elements that define the microstructure. The main peaks are placed at a temperature near $335^{\circ} \mathrm{C}$ for low preaging times, corresponding to the precipitationrecrystallization reaction, and at $322^{\circ} \mathrm{C}$ for high preaging times, where undoubtedly a great amount of recrystallization and precipitation has occurred (mainly for $500 \mathrm{~min}$ at $300^{\circ} \mathrm{C}$ with $90 \%$ of the precipitation-according to Luiggi [9]). The second peak, regardless of preaging and associated with the precipitation of the stable $\mathrm{Al}_{3} \mathrm{Fe}$ phase, occurs at $485^{\circ} \mathrm{C}$. The transition between both reactions shows a difference in $\Delta S$ of $-0.1 \mu \mathrm{V} / \mathrm{K}$ only explained by a significant introduction of $\mathrm{Si}$ atoms in the solution and a few $\mathrm{Fe}$ atoms, which regroup when temperature increases in order to generate said stable phase. The derivative of $\Delta S$ versus $T$ (not shown) established, just like in earlier cases, the transformation details. Figure 4(b) shows an amplified version of the behavior of $\Delta S$ in the first heating stage for high preaging times. In it the appearance of an intermediate, well-defined peak can be observed for preaging periods greater than or equal to 50 minutes before the precipitation peak of the $\alpha$-AlFeSi phase. The size of $\Delta S$, in the beginning, indicates that every $S i$ atom and, to a great extent, the Fe atoms have precipitated, whereas the first decrease in $\Delta S$ corresponds to the dissolution of the GuinierPreston zones and possibly to the recovery of the microstructure. The peaks around $275^{\circ} \mathrm{C}$ reflect great recovery and atom rearrangement activity inherent to recrystallization, while the peaks towards $320^{\circ} \mathrm{C}$ correspond to the formation of the $\alpha$-AlFeSi phase, which occurs, depending on the variation magnitude of $\Delta S$, as the result of structural rearrangement rather than as impoverishment of the solid solution. The fact that the peak associated with the precipitation of the $\alpha$-AlFeSi phase does not appear displaced in this figure but for lower preaging times is a consequence of the previous energy relaxation of the system produced by preaging, which is greater for longer preaging times.

4.1.3. Preaging for 10 Minutes at Different Temperatures in Severely Rolled Samples (85\%). The objective of this experience is to regulate the extent of atom supersaturation and to reduce the concentration of internal stresses as we increase temperature. The homogenized sample rolled to $85 \%$ reduction in thickness presents a combination of concentration of internal stresses and high atom supersaturation; hence, the 10-minute stay at each temperature fosters the precipitation of solute at that temperature, as well as recovery and recrystallization. The initial values for $\Delta S$, after preaging at different temperatures, are shown in the 4th row of Table 2, where we observe that $\Delta S$ increases as preaging temperature also increases, just up to $T=350^{\circ} \mathrm{C}$, to then diminish irregularly around $-0.14 \mu \mathrm{V} / \mathrm{K}$ for preaging at greater temperatures, which means that, up to $350^{\circ} \mathrm{C}$, a decrease of the solute in the solid solution occurs simultaneously due to the precipitation

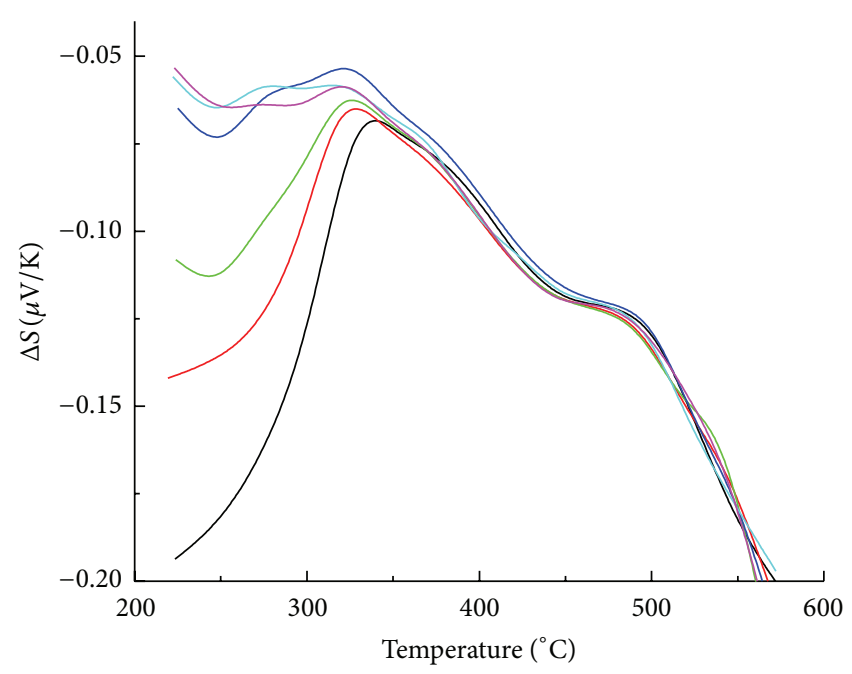

(a)

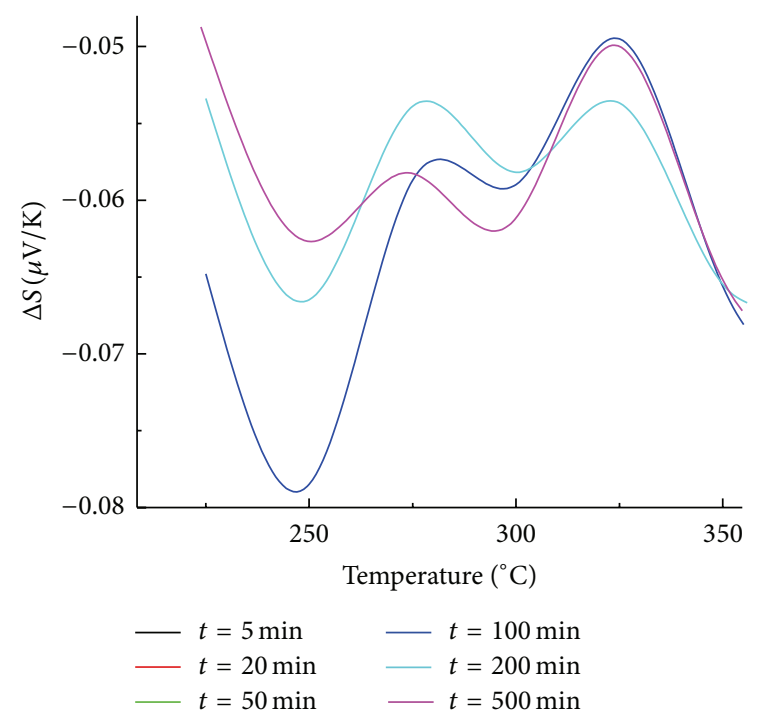

(b)

Figure 4: (a) Thermoelectric power versus temperature for 85-DHS samples preaged during different times at $300^{\circ} \mathrm{C}$, then annealed isochronously for 25 minutes at each temperature. (b) Amplified initial part of curve (a) for high preaging times at $300^{\circ} \mathrm{C}$.

of $\alpha$ and to a decrease in the concentration of internal stresses by the relaxation of the deformed matrix due to the release of energy by elimination of dislocations during preaging. The decrease in $\Delta S$ at higher temperatures implies both a lesser fraction of solute brought into the solution and atom redistribution at those temperatures.

Figure 5(a) shows the variation in $\Delta S$ as a function of temperature for preaging at temperatures above $250^{\circ} \mathrm{C}$ which, aside from confirming the results of Table 2, allows us to visualize the behavior during the isochronous heating already mentioned. Two types of behavior limited by the curve at $350^{\circ} \mathrm{C}$ are reported. Below such temperature, two exothermic transformations are reported, as discussed in the previous cases where reduction in atom concentration and internal 
TABLE 2: Thermoelectric power of MHD samples with thickness reduction to $85 \%$. Preaged at $300^{\circ} \mathrm{C}$ for different times (2nd row) and for 10 minutes at different $T$ (4th row). Measurements made immediately after treatment.

\begin{tabular}{lccccccc}
\hline Preaging time $(\mathrm{min})$ & 0 & 5 & 20 & 50 & 100 & 200 & 500 \\
\hline$\Delta S(\mathrm{~V} / \mathrm{K})$ & -0.3090 & -0.2058 & -0.1455 & -0.1070 & -0.0675 & -0.0625 & -0.0615 \\
\hline Preaging $T\left({ }^{\circ} \mathrm{C}\right)$ & As-Cast & 250 & 300 & 350 & 400 & 450 & 500 \\
\hline$\Delta S(\mathrm{~V} / \mathrm{K})$ & -0.4255 & -0.2371 & -0.1726 & -0.1050 & -0.1444 & -0.1378 & -0.1580 \\
\hline
\end{tabular}

strain are not enough to introduce modifications regarding the HS samples. At $350^{\circ} \mathrm{C}$, the evolution of $\Delta S$ appears different from that of previous cases, with a maximum located $70^{\circ} \mathrm{C}$ below the maxima reported in the two preceding curves and a slower transition between the two exothermic reactions, which begs the assumption of a strong interaction between recrystallization and precipitation in the $\alpha$ phase. For $350^{\circ} \mathrm{C}<\mathrm{T}<500^{\circ} \mathrm{C}$, three exothermic transformations clearly occur: the first one near $275^{\circ} \mathrm{C}$, the second one around $340^{\circ} \mathrm{C}$, and the third at $475^{\circ} \mathrm{C}$. While the last two reactions have been present in every kinetics study, the first peak seems to be a direct result from the relaxation of the deformed matrix, where 10 minutes at those temperatures, along with the respective isochronous treatment, is not sufficient to produce complete recrystallization of the sample studied.

Also note that preaging at $500^{\circ} \mathrm{C}$ tends to reproduce the behavior of the homogenized sample. In every curve shown, transformation towards $475^{\circ} \mathrm{C}$ appears bereft of the effects from recrystallization; hence, we consider that the matrix relaxation process was completed in its entirety. Figure 5(b) shows the corresponding derivatives confirming the above: a sequence of transformations vindicating the precipitation of $\alpha$ phase and $\beta$ phase, the first one interacting directly with the recrystallization process and the second, independent of it, in some cases generating exothermic transformations within the temperature recrystallization range that can only be associated with that process. In conclusion, the curves shown confirm three aspects: (1) values of $\Delta S$ reported can be in agreement with the theory only if the alloying Fe actively participates in the conformation of the existing phases; (2) precipitation at temperatures below $400^{\circ} \mathrm{C}$ of the $\alpha$-AlFeSi phase and its interaction with the recrystallization process; (3) precipitation of the $\mathrm{Al}_{3} \mathrm{Fe}$ phase at temperatures above $400^{\circ} \mathrm{C}$, where the growth process of the recrystallized grains seems not to modify its kinetics of precipitation.

4.2. Differential Scanning Calorimetry. All DSC measures were made during continuous heating under different microstructure conditions.

4.2.1. Deformation Effect from Rolling. Figure 6 shows a graph of heat flow versus temperature for the AA8011 alloy under three initial microstructure conditions: homogenized (HS), homogenized and rolled to 50\% in thickness reduction (50DHS), and homogenized and rolled up to $85 \%$ in thickness reduction (85-DHS). Figure 6(a), where the heating rate is $\Phi=d T / d t=5^{\circ} \mathrm{C} / \mathrm{min}$, shows the presence of three exothermic reactions at $90^{\circ} \mathrm{C}, 278^{\circ} \mathrm{C}$, and $466^{\circ} \mathrm{C}$ for the $\mathrm{HS}$ sample (empty circles), each corresponding to the formation of Guinier-Preston zones, the $\alpha$-AlFeSi phase, and the $\beta$ $\mathrm{Al}_{3} \mathrm{Fe}$ phase $[3,13]$, respectively. This behavior tends to stay for low deformations, though a clear variation in entropy is manifest, as seen by the widening of the exothermic peaks. For 85-DHS, there is a clear effect on each of the peaks. The characteristic peak of the precipitation of the GP zones, though manifested, is diffuse, implying that an important redistribution of solute atoms is produced during rolling, inhibiting part of the exothermic reaction associated with the GP zones, though its position seems invariable regardless of temperature.

The exothermic reaction that characterizes the precipitation of the $\alpha$ phase in HS gives way to two exothermic reactions, one at $288^{\circ} \mathrm{C}$ and the other at $328^{\circ} \mathrm{C}$, where both peaks are at temperatures above the value reported for the homogenized condition, implying that rolling slows down the precipitation process of the $\alpha$ phase. Even though both peaks appear at temperatures lower than those obtained with thermoelectric power measurements, they are without a doubt a consequence of both the recovery and recrystallization process, as well as of the precipitation process.

Given that, generally, recrystallization precedes precipitation [3, 12], it may be established that the first one is inherent to recrystallization, and the second is essential also to precipitation of the $\alpha$ phase, therefore proving the interaction between precipitation and recrystallization. Similarly, the peak for the $\beta$ precipitation is also broken down into two exothermic reactions at $454^{\circ} \mathrm{C}$ and $502^{\circ} \mathrm{C}$, respectively, the value for the $\beta$ peak remaining interlocked in homogenized condition between both reactions. Again, with the data currently available it is difficult to assign any given particular reaction to each transformation; however, given the high temperature at which they occur where, according to our previous $\Delta S$ studies, recrystallization has already occurred, the peaks can thus be associated with the $\beta$ phase precipitation, the $\Theta$ precipitation, and the growth of recrystallized grains. Possibly, this very last one is present in both exothermic events. Note that unlike our previous work [13] where the peak was associated with recrystallization, in the present work, which is a product of other techniques, such a contention must be discarded and the mechanisms involved that must be established are, besides the precipitation of the $\beta$ and $\Theta$ phases, the growth of recrystallized grains. The endothermic reactions inherent to the reversion of the processes described above are displaced towards the low temperatures as the degree of rolling is increased, indicating that deformation creates pathways for an easy reversion of the phases formed.

Figure 6(b) depicts the same study above but at a heating rate of $10^{\circ} \mathrm{C} / \mathrm{min}$, plotted from $200^{\circ} \mathrm{C}$. The exothermic 


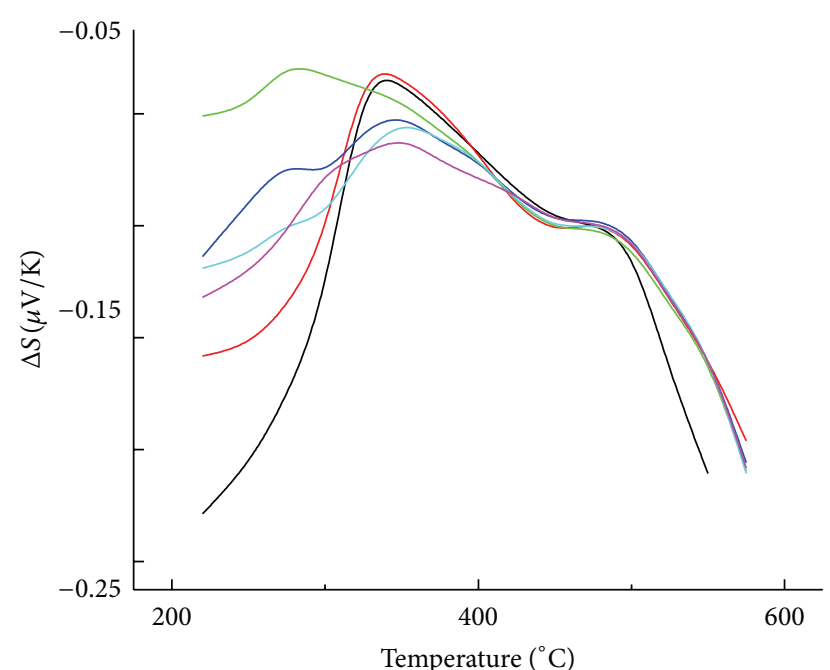

(a)

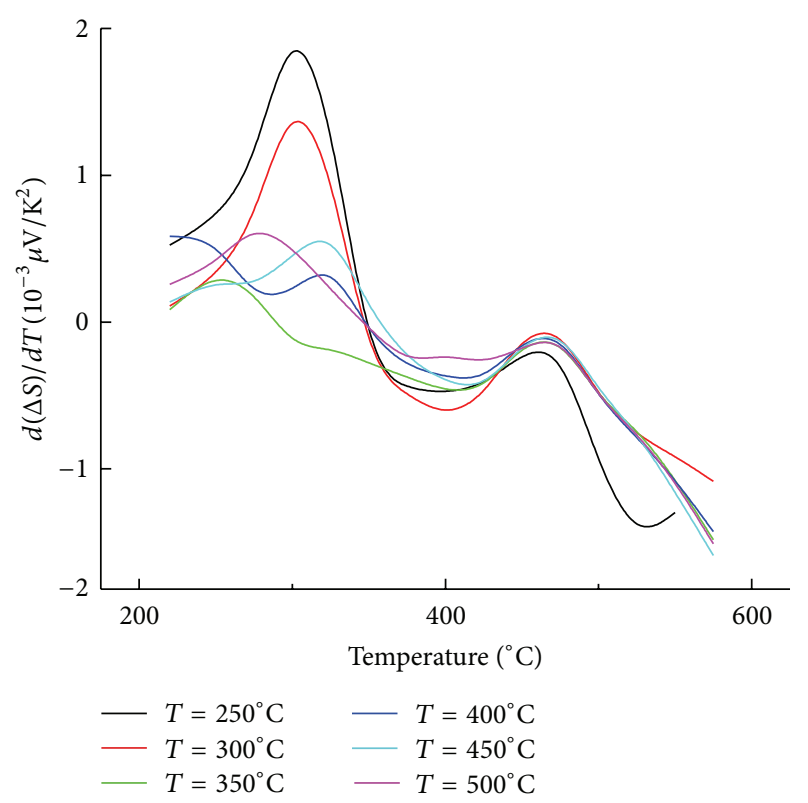

(b)

FIGURE 5: (a) Thermoelectric power and (b) derivative of the thermoelectric power versus temperature for the homogenized AA8011 alloy, for 85-DHS samples, subjected to preaging for 10 minutes at different temperatures.

reaction inherent to precipitation of the GP zones is not manifested in the thermogram, although the endothermic reaction inherent to its dissolution is reported, the behavior of which is similar to the one already proposed, indicating an increase in the dissolution rate as deformation increases. For HS samples, temperatures of the characteristic peaks for precipitation of the $\alpha$ and $\beta$ phases are at $300^{\circ} \mathrm{C}$ and $471^{\circ} \mathrm{C}$, respectively, while the endothermic trough that announces the end of the decomposition of the $\alpha$ phase is at $410^{\circ} \mathrm{C}$. For a reduction in thickness of $50 \%$, a tendency towards the appearance of two exothermic reactions ensues around $300^{\circ} \mathrm{C}$, one of which is associated with precipitation and the

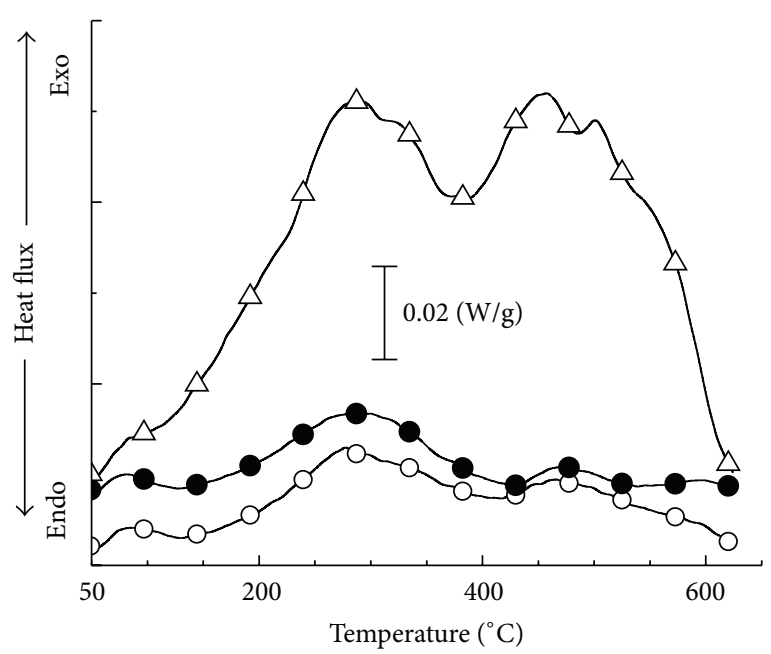

(a)

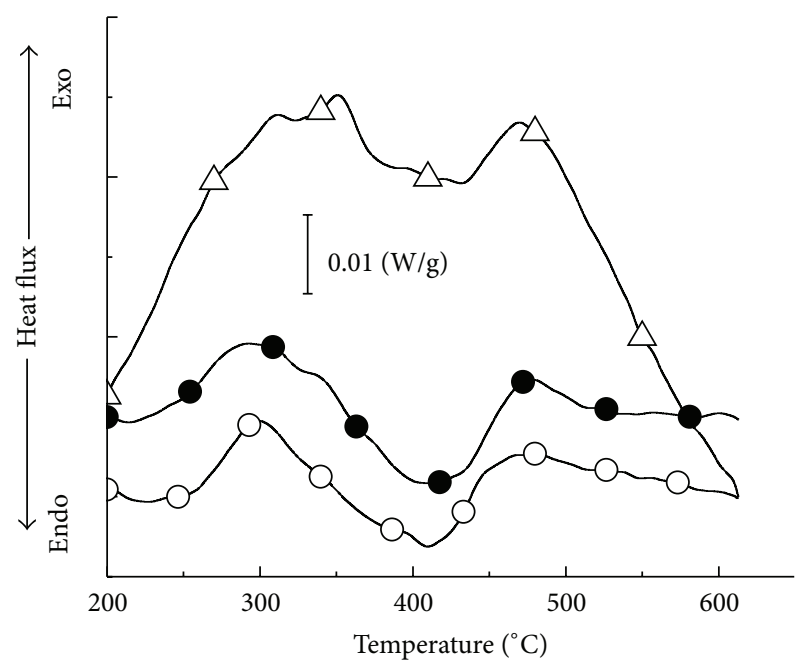

(b)

Figure 6: Heat flow versus temperature for the AA8011 alloy under three initial microstructures: O homogenized (HS), $\bullet$ homogenized and rolled to a $50 \%$ reduction in thickness (50-DHS), and $\triangle$ homogenized and rolled to an $85 \%$ reduction in thickness (85-DHS). (a) $\Phi=5^{\circ} \mathrm{C} / \mathrm{min}$ (from [13]) and (b) $\Phi=10^{\circ} \mathrm{C} / \mathrm{min}$.

other with recrystallization, whereas one single peak appears in the exothermic reaction observed at higher temperatures. For an 85\% reduction in thickness, these effects are stronger, while the two first exothermic reactions appear at $311^{\circ} \mathrm{C}$ and $352^{\circ} \mathrm{C}$, with a greater apparent entropy for the second peak. These two reactions are associated with the recrystallization and precipitation process of the $\alpha$ phase. The transition towards the $\beta$ phase is slower than in previous cases, showing one single exothermic peak at $471^{\circ} \mathrm{C}$. Undoubtedly, this peak is associated mainly with both $\beta$ phase precipitation and growth of recrystallized grains.

4.2.2. Effect of the Heating Rate ( $\Phi)$ on Homogenized and Deformed Microstructures. Figure 7(a) shows homogenized samples of thermograms made at different heating rates $\Phi$ : $5,10,20$, and $40^{\circ} \mathrm{C} / \mathrm{min}$. The inset shows $\Phi=5^{\circ} \mathrm{C} / \mathrm{min}$ in 


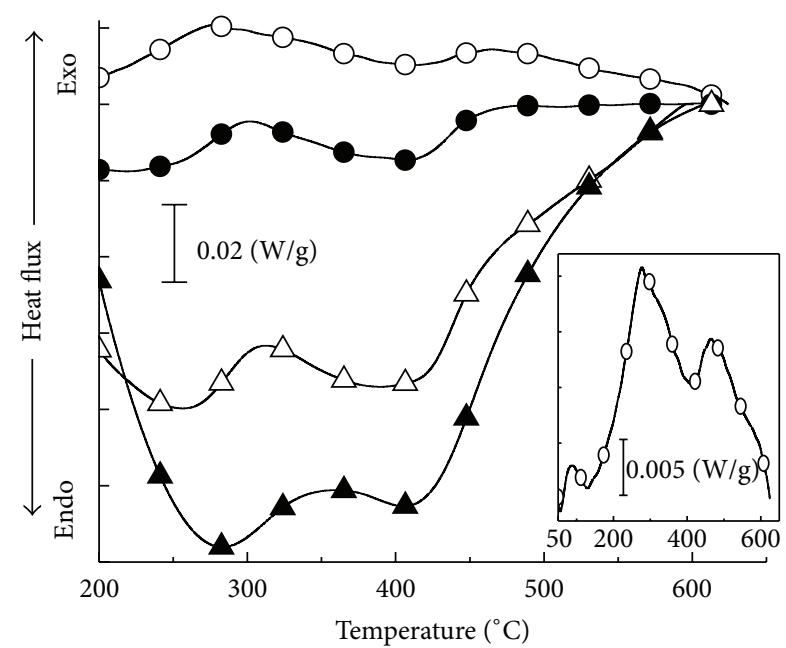

(a)

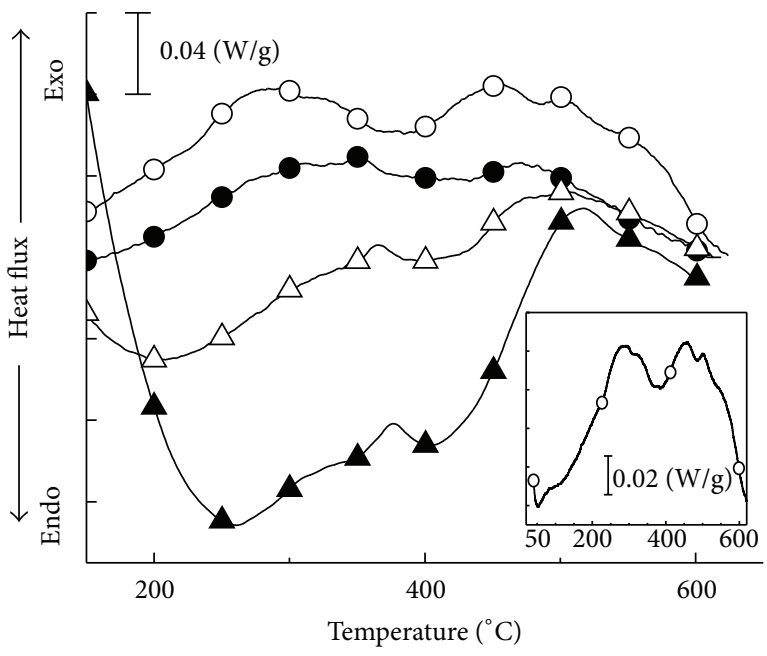

(b)

Figure 7: Effect of the heating rate on the heat flow. (a) Homogenized samples. (b) Severely deformed samples (from [13]): 0 $5^{\circ} \mathrm{C} / \mathrm{min}, 10^{\circ} \mathrm{C} / \mathrm{min}, \triangle 20^{\circ} \mathrm{C} / \mathrm{min}$, and $\Delta 40^{\circ} \mathrm{C} / \mathrm{min}$.

order to show the whole temperature range studied. Here, we again highlight the three exothermic reactions at $90^{\circ} \mathrm{C}, 278^{\circ} \mathrm{C}$, and $466^{\circ} \mathrm{C}$ that correspond to the formation of the GuinierPreston zones, the $\alpha$-AlFeSi phase, and the $\beta-\mathrm{Al}_{3} \mathrm{Fe}$ phase, respectively. The effect of incrementing $\Phi$ is that of displacing said exothermic reactions towards high temperatures, having the effect that some reactions will not be detected because $\Phi$ is higher than the reaction rate, just as it happens with precipitation of the GP zones at high $\Phi$. Note that even if, at high $\Phi$, the evolution of the kinetics of the $\alpha$ phase can be followed, the same does not occur with the $\beta$ phase because a collapse associated with the casting of the sample seems to occur, not allowing us to ascertain its kinetics at such high temperatures.

Figure 7(b) shows the effect of heating at different $\Phi$ rates on homogenized and rolled samples with $85 \%$ reduction in thickness (85-DHS). The inset highlights the thermogram at $5^{\circ} \mathrm{C} / \mathrm{min}$ covering the whole temperature range, the effect of deformation in the first heating stage, and the subsequent appearance of four exothermic transformations, the interpretation of which was given in part (b) of the preceding figure. For $\Phi>5^{\circ} \mathrm{C} / \mathrm{min}$, thermograms maintain the double exothermic reaction around the reaction that leads to precipitation of the $\alpha$ phase, obviously displaced because both the nucleation and recrystallization processes are thermally triggered so that the higher the $\Phi$ value, the higher the temperatures to which these peaks, not always well defined, are displaced. Note also that the two exothermic reactions that appear at high $T$ for $\Phi=5^{\circ} \mathrm{C} / \mathrm{min}$ disappear for higher heating rates, and only one exothermic reaction appears, just like in the thermoelectric power measurements, near $475^{\circ} \mathrm{C}$ for $10^{\circ} \mathrm{C} / \mathrm{min}$, at $485^{\circ} \mathrm{C}$ for $20^{\circ} \mathrm{C} / \mathrm{min}$ and at $516^{\circ} \mathrm{C}$ for $40^{\circ} \mathrm{C} / \mathrm{min}$. This behavior may be explained by the difference existing between the reaction rate of the $\beta$ phase precipitation and the growth rate of the recrystallized grains which, in addition to the increment in heating rate, generate the superimposition of both mechanisms. Again, as supported by previous $\Delta S$ studies, the interpretation of the recovery and recrystallization processes in the present work is slightly different from the one given in [13].

4.2.3. Effect of Preaging on Samples Severely Deformed at Different Temperatures. Figure 8 shows thermograms of 85DHS samples, preaged at fixed temperatures across different times, measured at $\Phi=5^{\circ} \mathrm{C} / \mathrm{min}$. Figure 8(a) shows the results for 20 min preaging at $300^{\circ} \mathrm{C}$ (solid circles) and at 50 minutes (solid triangles) and without preaging (empty circles). It is expected that, in aluminum alloys, preaging in HS samples will erase the exothermic transformation that characterizes the precipitation of the Guinier-Preston zones [20]. Such an effect would also be expected for deformed samples, however, depending on the alloying element, temperature, preaging time, and deformation degree. We can observe in the figure that, for 85-DHS samples, an exothermic transformation still appears near $90^{\circ} \mathrm{C}$, which becomes greater as the preaging time increases. One possible explanation for such behavior may be found in the presence of dislocation entanglements distributed in such a way that they hinder free atom diffusion and hence the less favorable entropic answer when the sample is more deformed. Preaging for 20 minutes at $300^{\circ} \mathrm{C}$ tends to reduce such ripples and to improve the diffusion pathways. This effect seems to appear in the fusion of the double recrystallization and precipitation peak which, just like in thermoelectric power, generates one single, ample, and extended peak. The $\alpha \rightarrow \beta$ transition zone also becomes slow due to the same treatment, so that, finally, the exothermic reaction from the $\beta$ phase precipitation is generated, the position of which seemingly stays without change at $460^{\circ} \mathrm{C}$ after preheating. These effects tend to smoothen, when the sample is preheated for 50 minutes at $300^{\circ} \mathrm{C}$, while only a few signs of the recrystallization process are left.

Figure 8 (b) shows the effect of preaging at $400^{\circ} \mathrm{C}$ for 20, 50, and 100 minutes. These thermograms confirm the behavior noted at $300^{\circ} \mathrm{C}$ regarding the effect of preaging 


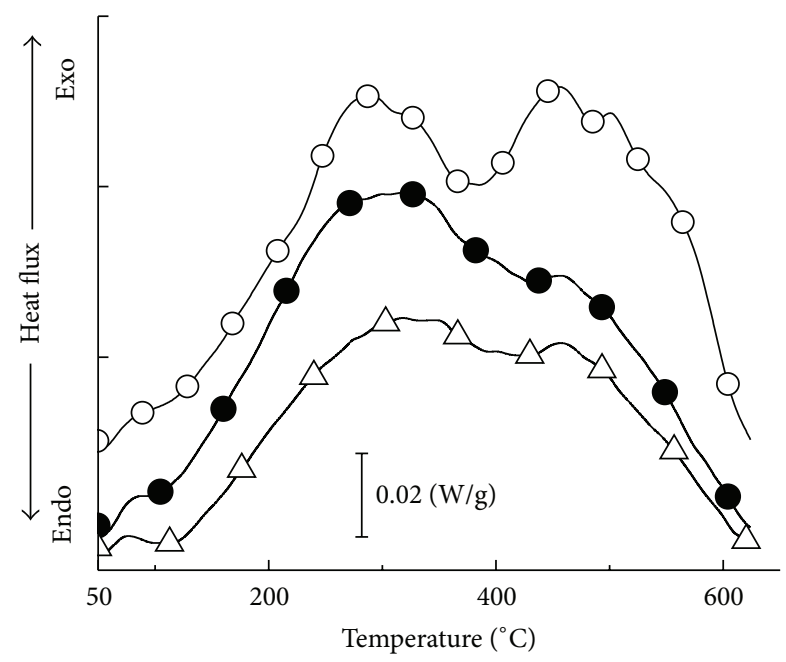

(a)

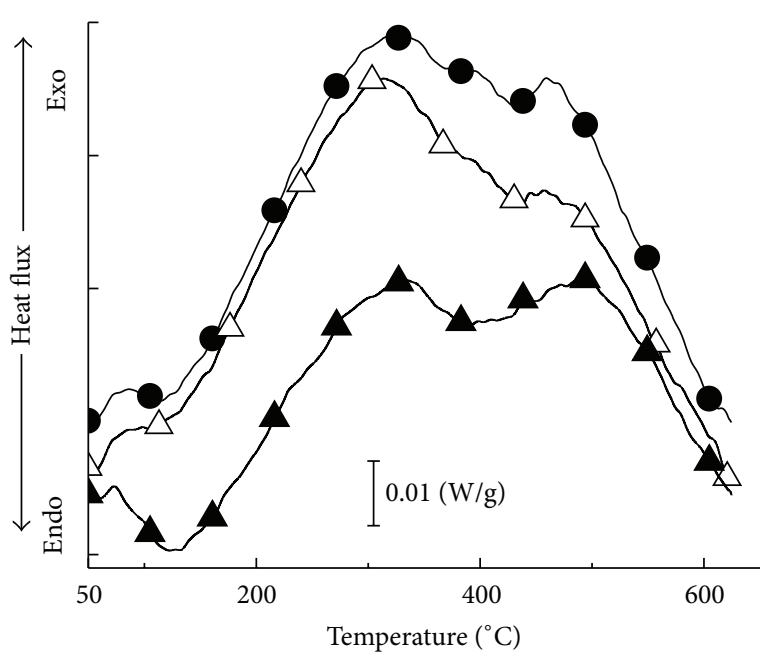

(b)

FIGURE 8: Effect of preaging on samples severely deformed at $5^{\circ} \mathrm{C} / \mathrm{min}$. (a) $\mathrm{T}=300^{\circ} \mathrm{C}$ and (b) $\mathrm{T}=400^{\circ} \mathrm{C}$. $\mathrm{O}$ without preaging, $20 \mathrm{~min}$ at $T, \triangle 50 \mathrm{~min}$ at $T$, and $\Delta 100 \mathrm{~min}$ at $T$.

around the first exothermic reaction. A notable difference occurs at the reversion level of the first peak for $100 \mathrm{~min}$ preaging at $400^{\circ} \mathrm{C}$, where most certainly the recrystallization process has been completed during preaging. The behavior of the second and third exothermic reaction tends to be free of recrystallization. These thermograms are evidence of the precipitation-recrystallization interaction sequence starting from the severely deformed sample (Figure $8(a)$ ) through different stages where atom supersaturation and the concentration of internal stresses are reduced, tending, specifically in the case for 100 minutes at $400^{\circ} \mathrm{C}$, to have a behavior close to that of the homogenized sample, conveying the idea that full recrystallization has occurred. Even though it is not shown, preaging at $500^{\circ} \mathrm{C}$ was also checked at different times, where it was evident that the reactions associated with recrystallization were not present, in agreement with our previous analysis.

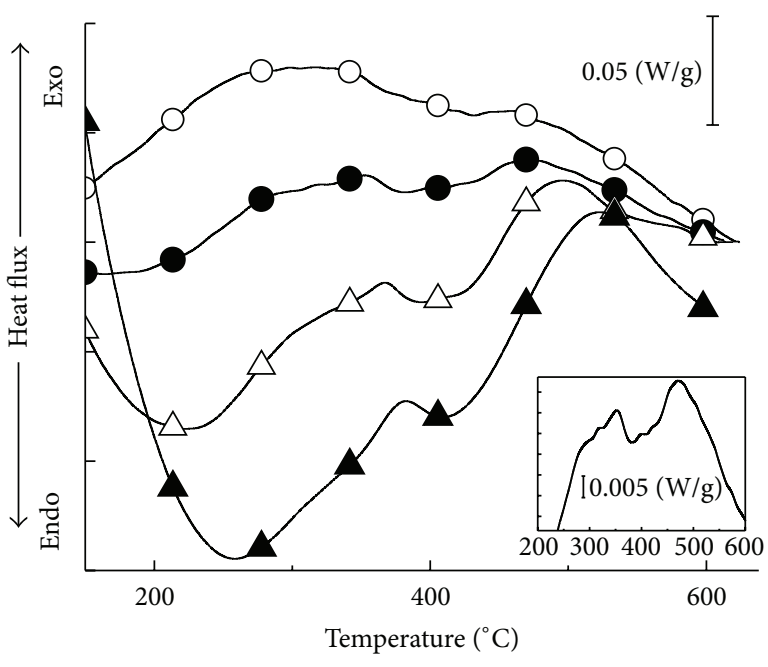

(a)

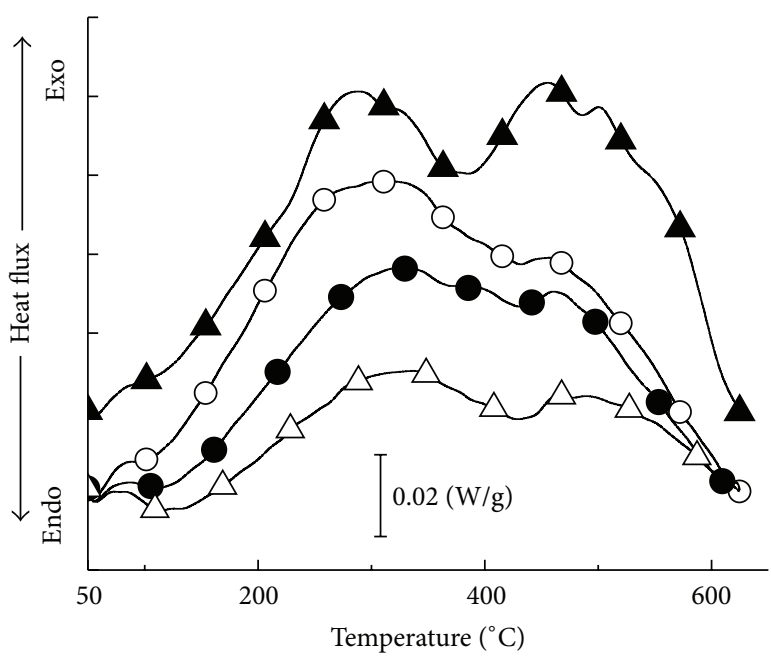

(b)

FIgURE 9: Thermograms of 85-DHS samples. (a) Effect of the heating rate for samples pre-heated for 20 minutes at $300^{\circ} \mathrm{C}$ (same notation as Figure 7). (b) $20 \mathrm{~min}$ preheating at different temperatures measured at $5^{\circ} \mathrm{C} / \mathrm{min}$. $\Delta$ without preheating. $\bigcirc T=300^{\circ} \mathrm{C}$. $T=400^{\circ} \mathrm{C}$. $\triangle T=500^{\circ} \mathrm{C}$.

\subsubsection{0 min Preaging at Different Heating Rate and Temper-} atures in 85-DHS Samples. The thermogram of Figure 9(a) shows the effect of different $\Phi$ on samples severely deformed and preaged for 20 minutes at $300^{\circ} \mathrm{C}$. The thermogram at $5^{\circ} \mathrm{C} / \mathrm{min}$ was discussed before. The inset shows the amplified version of the thermogram for $\Phi=10^{\circ} \mathrm{C} / \mathrm{min}$, where the transformation details are highlighted. In it, two peaks of high enthalpy are observed at $352^{\circ} \mathrm{C}$ and $470^{\circ} \mathrm{C}$, respectively; an exothermic reaction of lesser magnitude at $315^{\circ} \mathrm{C}$; and another small exothermic reaction at $400^{\circ} \mathrm{C}$ in the $\alpha \rightarrow \beta$ transition. This behavior confirms the precipitationrecrystallization interaction, where recrystallization corresponds to the peak at $315^{\circ} \mathrm{C}$, prior to the precipitation of the $\alpha$ phase, in total agreement with Gokhale et al. [3]. The reactions that occur at higher temperatures correspond 
to the growth of recrystallized grains and to the $\beta$ phase, respectively. Note the movement of each of the reactions towards higher temperatures as $\Phi$ increases, indicating that they occur by a diffusion mechanism. For high $\Phi$ values, the exothermic reactions that take place at high temperatures tend to combine into a single one, due to the difference between the reaction rates of both mechanisms.

Figure 9(b) shows the effect of preaging for $20 \mathrm{~min}$ utes at different temperatures $\left(300^{\circ} \mathrm{C}, 400^{\circ} \mathrm{C}\right.$, and $\left.500^{\circ} \mathrm{C}\right)$, including a reference without preaging, heated at $5^{\circ} \mathrm{C} / \mathrm{min}$. This figure confirms the effect of preheating on each of the phases: as the pre-heating temperature becomes higher, both the atom supersaturation and the dislocation density tend to abate, which translates into better defined exothermic reactions due to the greater energy accumulated in the absence of or little preheating time. In this figure, near $90^{\circ} \mathrm{C}$, the exothermic reaction associated to the recoveryprecipitation (GP zones) interaction is maintained, becoming more defined as the preheating temperature increases, due to the progressive completion of the recovery process. The corresponding exothermic reactions, due to the coexistence of the $\alpha$ phase precipitation and to recrystallization, both well defined in the thermogram without preaging (solid triangles), tend to appear as a single reaction for preaging processes at $500^{\circ} \mathrm{C}$, indicating that, at that temperature, the recrystallization process has been completed and the peak reported is due to the precipitation. This also applies to the reactions associated with the $\beta$ phase precipitation and the growth of recrystallized grains, which are transformed into one single peak because, at that temperature, the dislocation density is very low. An important aspect to be noted in this figure is the slight displacement of the precipitation peaks as the preaging temperature increases, confirming the existence of a lesser supersaturation and a smaller dislocation density in these cases.

The results obtained via DSC are coherent with the ones obtained via thermoelectric power, even though the temperatures at which these transformation peaks occur differ slightly, due to the response of the microstructure to the measurement technique used.

4.3. Transmission Electron Microscopy (TEM). The observations of the AA8011 alloy via TEM allow a microanalysis and ultrastructural analysis of the samples under different microstructure conditions generated by the different thermal and mechanical treatments, allowing direct access to the substructures of dislocations inside subgrains or at the grain boundaries, as well as to the phases and precipitates that are present and which have promoted interactions among themselves for the formation of the final structure of the material. A micrographic study of the AA8011 alloy was made by Gokhale et al. [3] under microstructure conditions different from the present work. They use heat-rolled samples, identify the recrystallization peak by DSC, and then age the sample at around the peak temperature. In the present work, the samples, whether deformed or not, are subjected to nonisothermal heating at a rate of $5^{\circ} \mathrm{C} / \mathrm{min}$ up to the temperature of the peak, and once the desired condition is achieved, the sample is quenched in a cold bath. Some

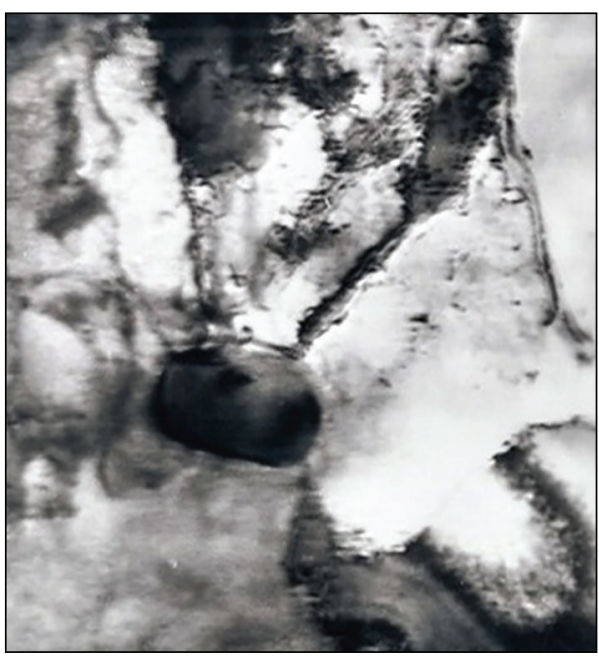

FIgURE 10: TEM micrograph of a cast AA8011 sample showing presence of particles, dislocations, grains, subgrains, and grain joints.

interesting work on deformed aluminum microstructures and derived alloys is to be found in the literature. The microscopy study exposed below is not intended to identify the phases present; however, it is well established that these phases are composed mainly of Al-Fe and Al-Fe-Si globular morphology $(\alpha-\mathrm{AlFeSi})$ and acicular $(\beta-\mathrm{AlFeSi})$ [21-24].

\subsubsection{Sample Cast, Homogenized, and Rolled to Different Reductions in Thickness}

(a) Cast Sample. Earlier research $[23,24]$ determined that, in the cast sample, there are zones of fragmented segregation and second-phase particles with a redistribution of segregates in the aluminum matrix, where the skeletal phase of the type known as "Chinese structure" can be appreciated. The micrograph of Figure 10 corresponds to a cast sample where a variety of linear defects and dislocation substructures are observed interacting with each other. Furthermore, high deformation zones typical of this type of cast samples are observed, which generate much potential energy (stored) that will eventually trigger precipitation and recrystallization mechanisms in the alloy. Also, particles of likely ovoid shape and size around $6 \mu \mathrm{m}$ are detailed, anchored to the lattice matrix, and interacting with a distribution of subgrains and dislocations, both inter- and transsubgranularly. These effects are typical of alloys subjected to a hot-rolling process. The anchor of the particle considerably limits later subgrain development, which affects the mechanical properties of the material, depending on the distribution and size of the grains.

(b) Homogenized Samples. We have taken the work of Torres et al. [24] as reference for the analysis of the homogenized sample. They observed intermetallic phases with a distribution in the matrix core; particles with spherical $(\alpha-\mathrm{AlFeSi})$ and needle-like ( $\beta$-AlFeSi) shape were reported. They also observed the presence of dispersed silicon particles, which embrittles the alloy by directly affecting its finish. Also, the 


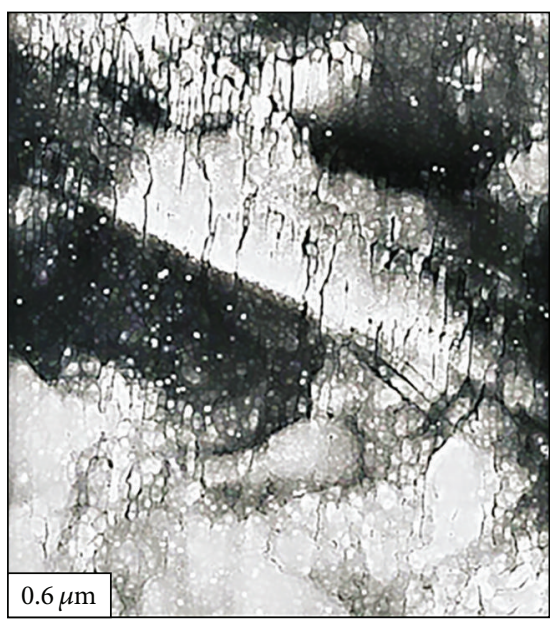

(a)

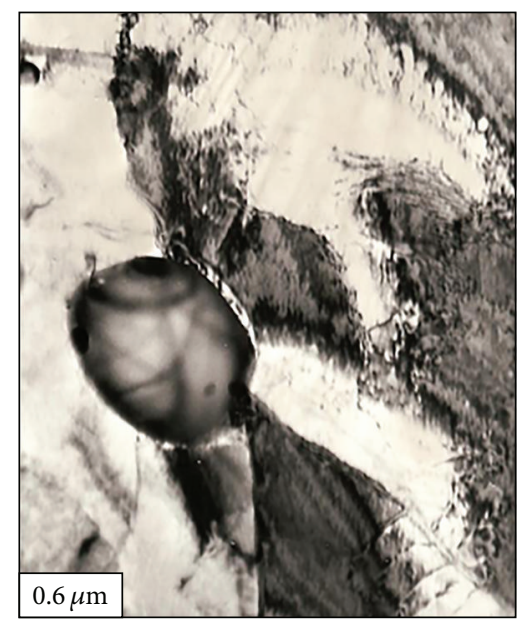

(b)

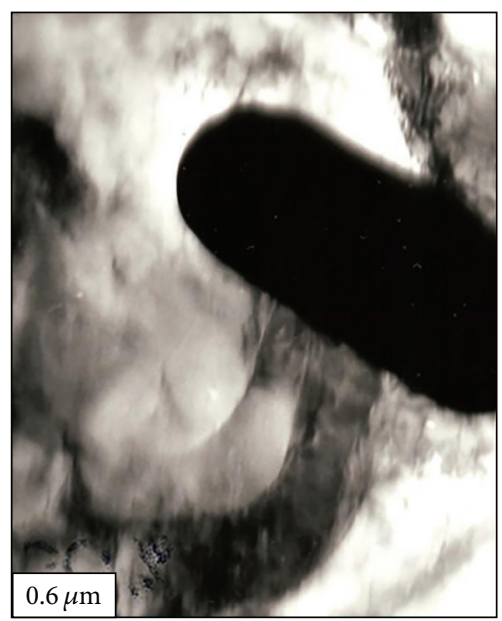

(c)

FIGURE 11: TEM micrographs of a 50-DHS sample, showing dislocation substructures and elongated particles with dislocations entangled in and around the grains.

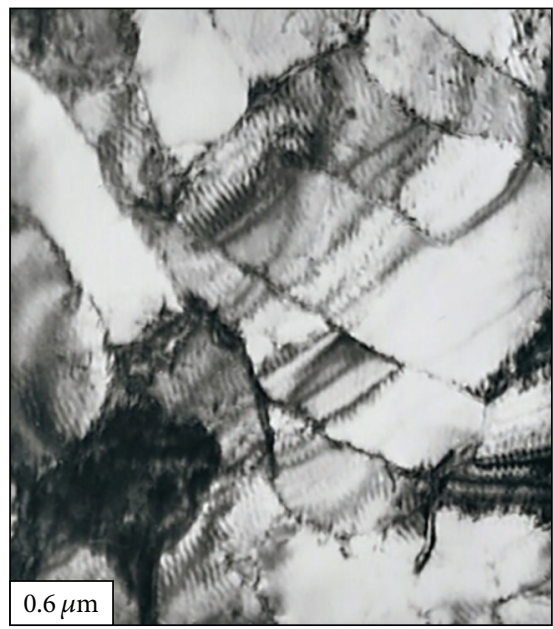

(a)

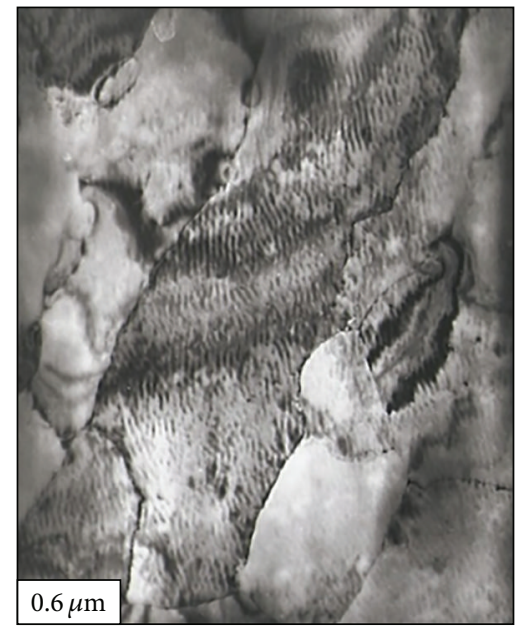

(b)

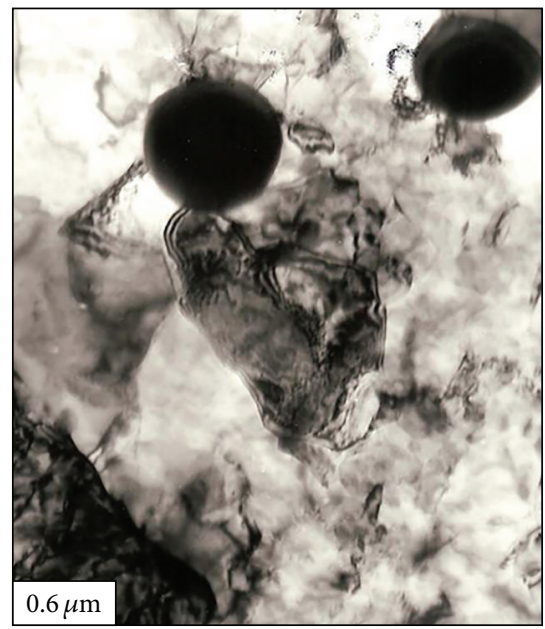

(c)

FIGURE 12: TEM micrographs of an 85-DHS sample, showing distribution of deformed grains and an elevated dislocations density.

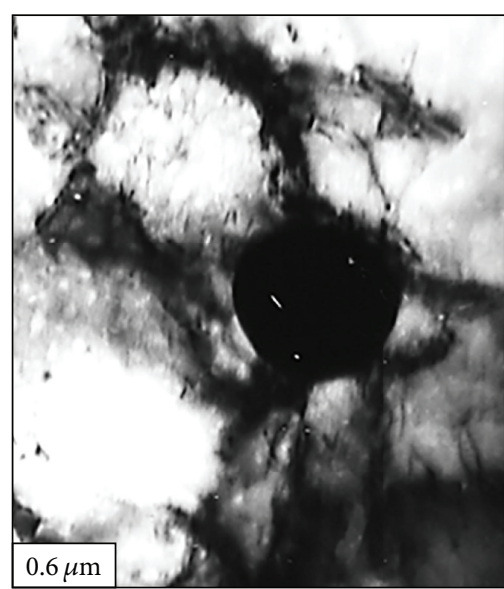

(a)

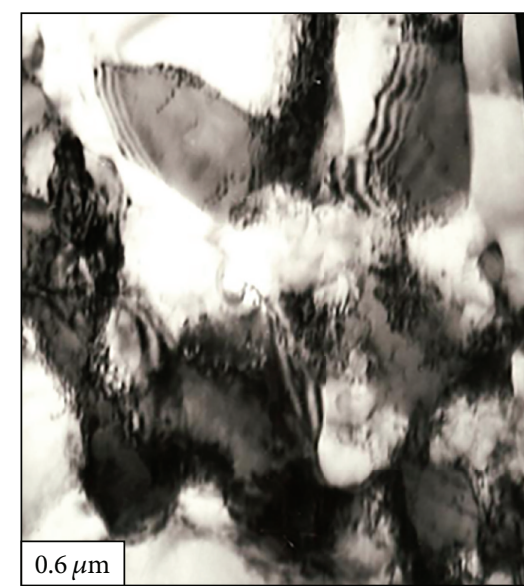

(b)

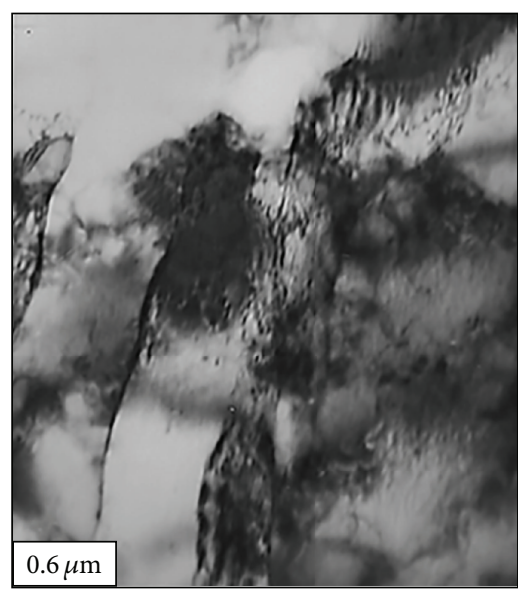

(c)

FIgURE 13: TEM micrograph of a 50-DHS sample, heated up to $90^{\circ} \mathrm{C}$ at a rate of $5^{\circ} \mathrm{C} / \mathrm{min}$. 


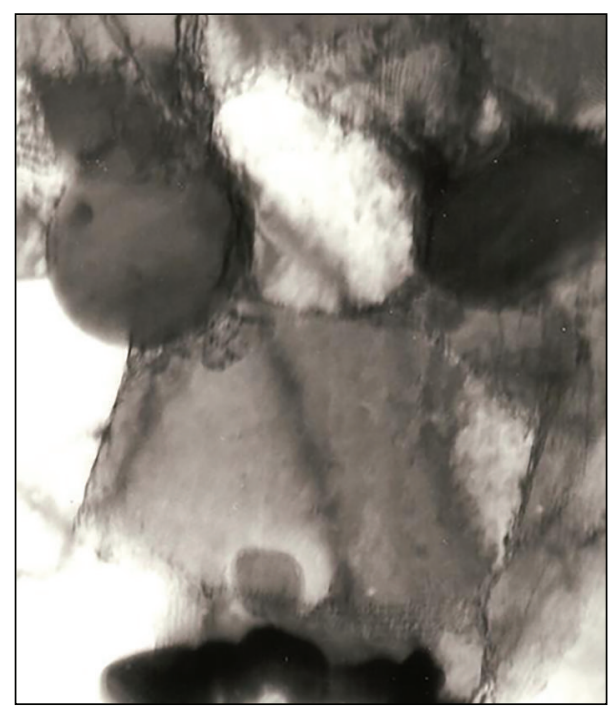

FIGURE 14: TEM micrograph of a 50-DHS sample heated up to $278^{\circ} \mathrm{C}$ at a rate of $5^{\circ} \mathrm{C} / \mathrm{min}$.

matrix shows low density dislocation zones and a grain distribution of different sizes.

(c) 50-DHSR Samples. Figure 11 shows the effect of rolling on a homogenized sample, subsequently rolled to a $50 \%$ reduction in thickness. Micrographs in Figures 11(a) and 11(b) show subgrains of different sizes lengthened by rolling, with welldefined contours. Also, numerous discontinuities tending to form dislocation substructures with different orientations at grain boundaries are observed in the matrix. This high dislocation density generates a very high accumulated energy potential that might greatly affect the recrystallization and precipitation process. Likewise, Figure 11(c) shows an elongated particle of approximately $12 \mu \mathrm{m}$ in which grains of irregular shape are anchored, with dislocations entangled in and around the grains, indicating a clear precipitate-grainsubgrain-dislocation interaction. Therefore, the dislocation density increases its distribution in disarray, arranging itself as a cobweb or jungle in the core of the matrix.

(d) 85-DHS Samples. Micrograph in Figure 12(a) shows the distribution of deformed grains and subgrains, oriented by the rolling process, with a high dislocation density that tends to redistribute, both inter- and trans-granularly in the material. Micrograph in Figure 12(b) shows the presence of irregular grains and subgrains of different sizes and high dislocation density on the grain edges or boundaries, a product of the high activity during formation. Likewise, micrograph in Figure 12(c) shows two spherical particles anchored, interfering with the trajectory of the dislocations and hindering the complete formation of grains and subgrains in the aluminum matrix. This anchorage of particles obeys the fractionation of particles of greater size into smaller ones due to the deformation process and to the reorganization suffered by the dislocations. However, when the degree of deformation is high, $85 \%$ in our case, the dislocation density increases and its redistribution is not uniform, the array of the grains becoming an entanglement in the core of the matrix; nonetheless, when deformation is too severe, the grains may annihilate each other or order themselves, providing evidence of grain boundaries as a product of polygonization.

\subsubsection{0-DHS and Annealed Samples (ADHS) at the DSC} Peak Temperatures. Micrograph in Figure 13 shows samples annealed at a rate of $5^{\circ} \mathrm{C} / \mathrm{min}$ up to a temperature near the temperature of the peak reported in DSC thermograms studied before. The microstructure for samples heated up to $90^{\circ} \mathrm{C}$ highlights (Figure 13(a)) the presence of a precipitate of spherical shape of approximately $6 \mu \mathrm{m}$ in diameter, with a relatively uniform subgrain distribution and a high density of dislocation substructures. The presence of few small precipitates is also noted.

Figures 13(b) and 13(c) highlight remnants of the rolling process with elongated grains as a product of the orientation of deformation and a distribution of dislocations around grains parallel to their interior. Besides the aforesaid microstructural elements, the appearance of bands where dislocations of varied thickness, subgrains, and bands interact is also observed. Apparently, the annealing temperature is not sufficiently high to produce a redistribution of the dislocation substructure.

Figure 14, on the other hand, shows micrographs for $T=$ $278^{\circ} \mathrm{C}$ corresponding to the presence of grains and subgrains of different sizes. Spherical particles interacting with a significant number of dislocations are observed, meaning that the recovery process unfolds slowly. Besides, dislocation structures are observed because the annealing temperature is not sufficiently high to produce a redistribution of dislocation structures.

Even though the precipitates have not been identified at this level, a direct interaction between these and the dislocation structures is seen, implying that the recoveryrecrystallization process is happening.

Figure 15 shows a micrograph corresponding to samples heated up to $T=466^{\circ} \mathrm{C}$, in which particles on the boundaries or edges of grains, dislocations interacting with the particles, and reorganization of dislocations are observed (Figure 15(a)) in the aluminum matrix, acquiring an orderly configuration. Figure 16(b) shows details of the same zone with dislocation lines superimposed on a recrystallized microstructure.

\subsubsection{5-DHS and Annealed Samples (ADHS) at the DSC} Peaks Temperature. Figure 16 shows two aspects of the samples heated up to $90^{\circ} \mathrm{C}$. Figure 16 (a) highlights the presence of lengthened grains with an important dislocation density, in the shape of bands, in the grain boundaries, and in the grain itself; however, unlike in the previous study, there are no dislocation entanglements. Figure 16 shows particles interfering with varied irregular grains and dislocations that try to surround the particles.

Figure 17 shows micrographs corresponding to a heating of up to $T=455^{\circ} \mathrm{C}$. Micrograph in Figure 17(a) shows the coexistence of a spherical particle, around $5 \mu \mathrm{m}$ in diameter, with a well-defined grain border, with an outstanding variety of inner dislocations and the appearance of recrystallized grains. Micrograph in Figure 17(b) shows the microstructure 


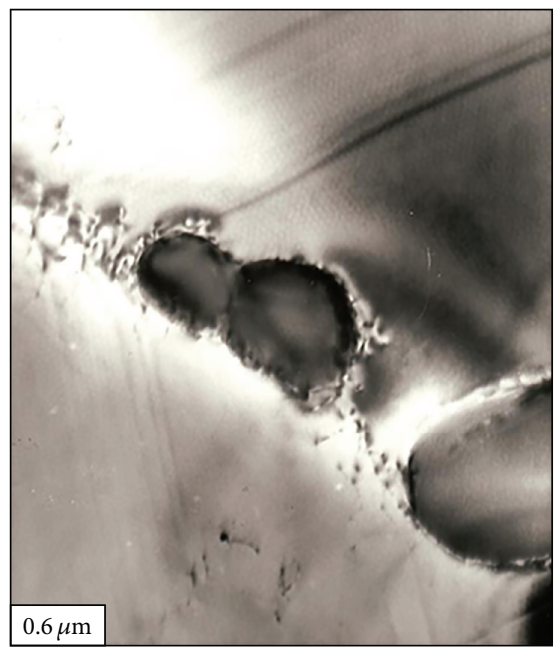

(a)

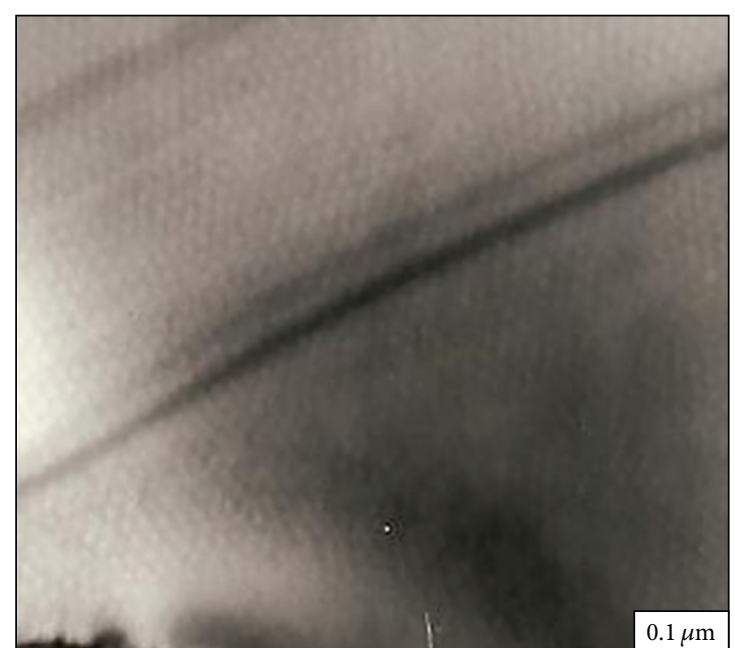

(b)

FIgURE 15: TEM micrographs of a 50-DHS sample heated up to $466^{\circ} \mathrm{C}$ at a rate of $5^{\circ} \mathrm{C} / \mathrm{min}$.

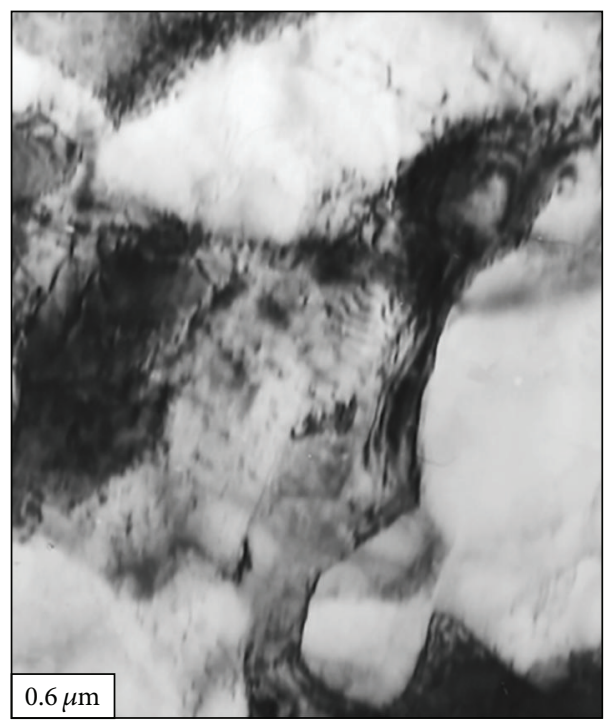

(a)

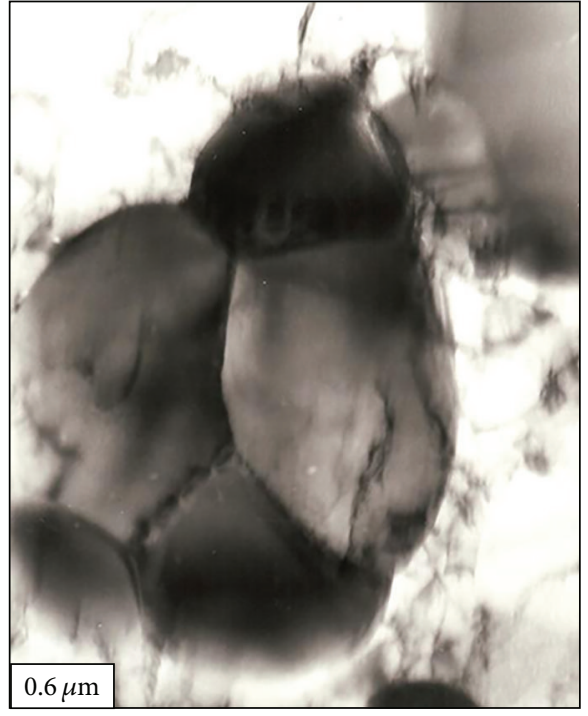

(b)

Figure 16: TEM micrographs of an $85-\mathrm{DHS}$ sample, heated up to $90^{\circ} \mathrm{C}$ at a rate of $5^{\circ} \mathrm{C} / \mathrm{min}$.

in the region of confluence of several grains or triple point. Very small precipitates interacting with the aluminum matrix, possibly dispersoids, are also observed.

Figure 18 shows a microstructure at $T=502^{\circ} \mathrm{C}$. A big ovoid-shaped particle is shown (Figure 18(a)) which seems not to interact strongly with the matrix and visibly recrystallized grains, while, in Figure 18(b), the presence of a great number of subgrains is highlighted; some are precipitates and some disorderly dislocations with different conformations are seen.

From the present microscopic study, we may infer that, as the degree of rolling increases, the degree of rollingborne deformation induces, up to a value, a growing and heterogeneously distributed dislocation density, originating a mess or jungle of dislocations at the core of the matrix, to be later reordered and even eliminated in severe deformations.

Continuous heating up to a certain temperature fosters both the release of energy stored in the form of dislocations and their rearrangement, in turn prompting the recrystallization and interaction with the precipitated phase at those temperatures. Definitely, the micrographs provided confirm that deformation creates preferential sites for the onset of the recrystallization and of the phases formed at specific temperatures, so that interaction of both processes is produced from the search of equilibrium. Deformation by rolling is a significant factor in the recrystallization and precipitation process, and the likelihood that the material reaches equilibrium as a consequence of the release of energy 


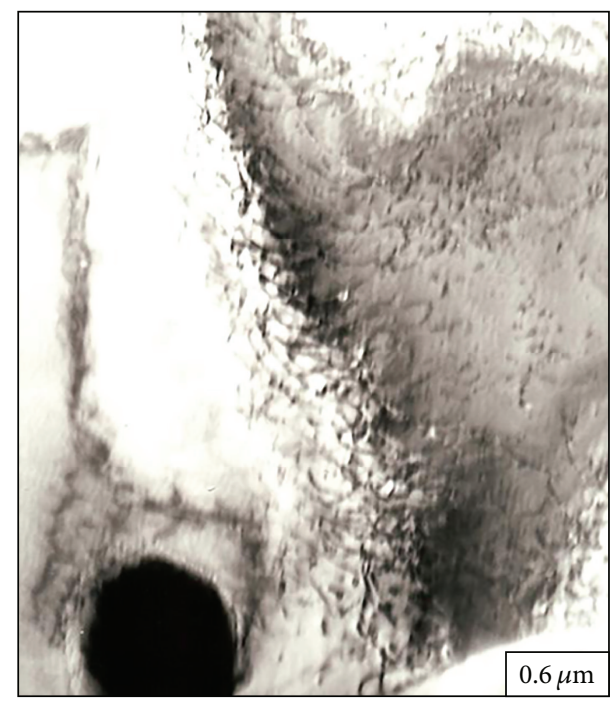

(a)

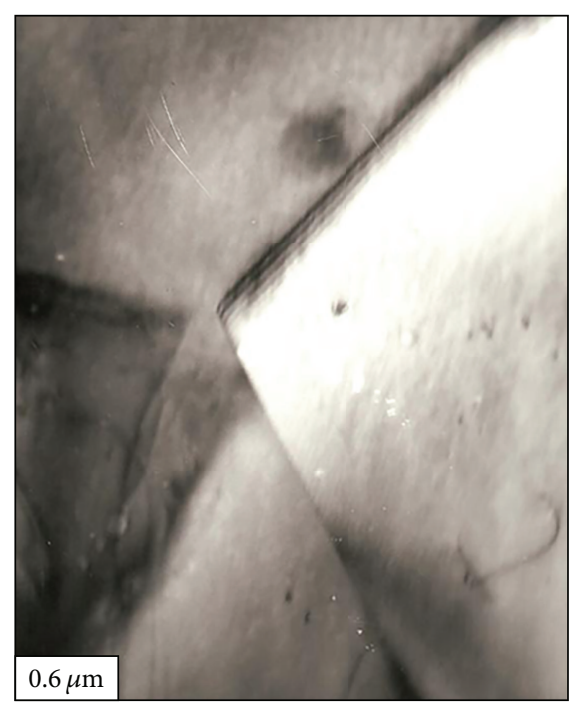

(b)

FIgURE 17: TEM micrographs of an $85-\mathrm{DHS}$ sample, heated up to $475^{\circ} \mathrm{C}$ at a rate of $5^{\circ} \mathrm{C} / \mathrm{min}$.

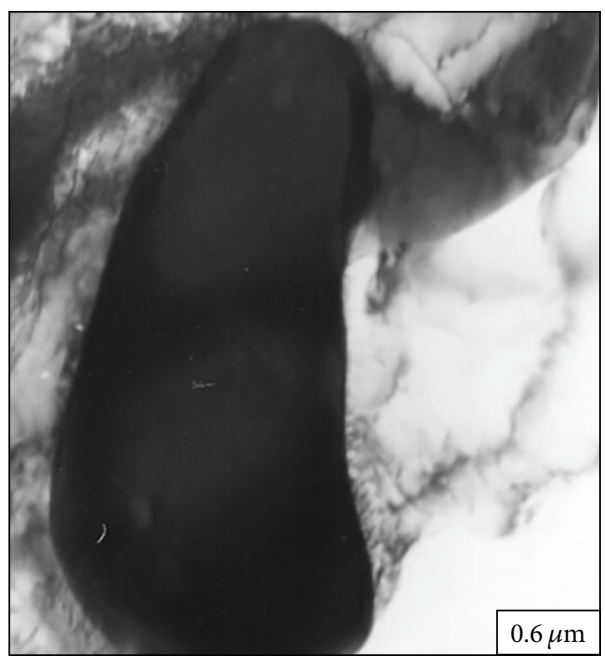

(a)

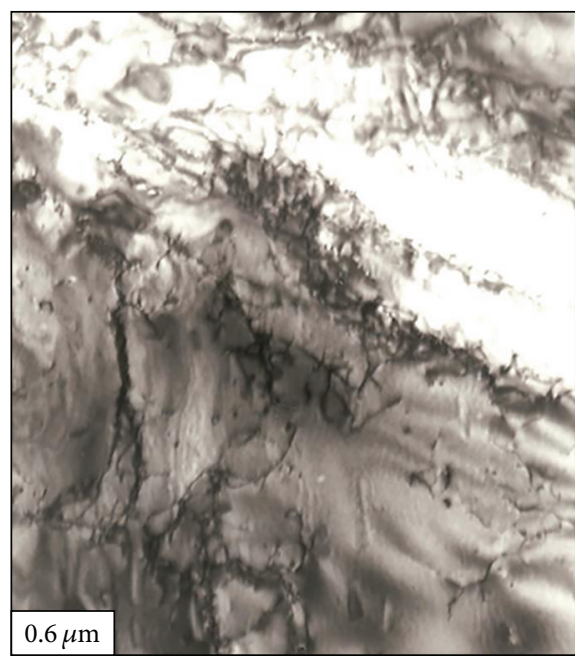

(b)

FIgURE 18: TEM micrographs of an $85-\mathrm{DHS}$ sample heated up to $502^{\circ} \mathrm{C}$ at a rate of $5^{\circ} \mathrm{C} / \mathrm{min}$.

absorbed during the work will depend on temperature and annealing time.

\section{Conclusions}

The AA8011 alloy has been exhaustively studied under different microstructures by thermoelectric power, differential scanning calorimetry, and transmission electron microscopy in order to prove the occurrence of precipitation and recrystallization under different conditions, prompting the following conclusions.

(1) The three techniques used reflect their sensitivity to the microstructural changes studied, the recrystallization and precipitation processes differing on the basis of the conditions of the samples, and the initial microstructure remaining regulated by the preaging treatments.

(2) Thermoelectric power studies establish the existence of two transformations in the HS samples associated with precipitation of the $\alpha$-AlFeSi below $400^{\circ} \mathrm{C}$ and $\beta-\mathrm{Al}_{3} \mathrm{Fe}$ near $470^{\circ} \mathrm{C}$, their transition occurring basically because of the rearrangement of $\mathrm{Fe}$ atoms in the precipitated phase. Rolling accelerates precipitation of $\alpha$ phase (DHS samples) up to a defined degree of deformation, suggestive of the reorganization of the dislocation structure and the interaction between the recrystallization and precipitation processes. The $\beta$ phase is less affected by the rolling process and the temperature range where precipitation occurs coinciding with that of recrystallized grains growth. 
The derivative of the thermoelectric power appears as a powerful tool for identifying microstructural changes, be it by recrystallization or by precipitation. In most cases, by means of this technique, both recrystallization and precipitation of $\alpha$ phase coincide on a single peak, broader than that inherent to precipitation.

(3) From the DSC studies, we conclude that the behavior obtained for $\Delta S$ is confirmed, including some additional points. For example, at low heating rates and in highly rolled samples, additional exothermic reactions appear. In this work, the reaction close to the precipitation peak of $\alpha$ phase is associated with recrystallization, while the reaction happening close to the $\beta$ phase is associated with the growth of recrystallized grains. Details of precipitation in the Guinier-Preston zones are included.

The evolution of the heat flow at different heating rates confirms that both the nucleation process and recrystallization are mechanisms thermally active, occurring by diffusion. Preliminary details of the activation energy inferred from this type of study are presented by Luiggi [13].

(4) TEM micrographs confirm the premises supporting the present work, reflecting that the rolling process introduces in the material a dislocation density that grows as the degree of deformation increases. At a low strain rate, the dislocations are distributed heterogeneously and disorderly, forming a dislocation entanglement, while, for high strain, the dislocation distribution tends to show a certain order. This fact explains the differences of behavior of DSC and $\Delta S$ for the different microstructures studied.

The micrographs show an interaction between precipitates and dislocations, reporting a total or partial recrystallization at the temperatures deduced from $\Delta S$ and DSC experiments.

A study elaborating on recrystallization interaction and on phase kinetics evolution in severely deformed samples at lower heating will be undertaken, to delve in the deconvolution of the kinetics where both processes occur simultaneously.

\section{Conflict of Interests}

The authors declare that there is no conflict of interests regarding the publication of this paper.

\section{Acknowledgments}

This work is supported by the Office of Academic Planning at the Universidad de Oriente through POA Project PN $5.5 / 2010$. The authors would also like to acknowledge Carlos Mota and his company Traduce, CA, for the translation of this paper.

\section{References}

[1] P. R. Rios, F. Siciliano Jr., H. R. Z. Sandim, R. L. Plaut, and A. F. Padilha, "Nucleation and growth during recrystallization," Materials Research, vol. 8, no. 3, pp. 225-238, 2005.

[2] E. P. Rocha Lima, R. A. Sanguinetti Ferreira, N. Freitas de Quadros, and Y. Prasad Yadava, "Estudo dos aspectos cinéticos e morfológicos durante recristalização da liga de alumínio aa 8011," Revista Iberoamericana de Ingeniería Mec, vol. 10, no. 1, pp. 131-137, 2006.

[3] A. M. Gokhale, C. V. Iswaran, and R. T. DeHoff, "Use of the stereological counting measurements in testing theories of growth rates," Metallurgical Transactions A, vol. 10, no. 9, pp. 1239-1245, 1979.

[4] F. J. Humphreys and M. Hatherly, Recrystallization and Related Annealing Phenomena, Pergamon Press, Oxford, UK, 2nd edition, 2004.

[5] R. A. Vandermeer, R. A. Masumura, and B. B. Rath, "Microstructural paths of shape-preserved nucleation and growth transformations," Acta Metallurgica et Materialia, vol. 39, no. 3, pp. 383-389, 1991.

[6] R. E. S. Puchi, B. Fajardo, and J. V. Valera, "Recrystallization of commercial twin-Roll Cast Aluminum-iron-silicon Alloy Homogenized at $853 \mathrm{~K}$," in Proceedings of the 4th International Conference on Aluminum Alloys, T. H. Sanders Jr. and E. A. Starke Jr., Eds., vol. 1, pp. 18-25, Atlanta, Ga, USA, 1994.

[7] W. H. Hildebrandt, "Differential scanning calorimetry evaluations of recrystallization behavior in aluminum sheet," Metallurgical Transactions A, vol. 10, no. 8, pp. 1045-1048, 1979.

[8] N. J. Luiggi, "Thermoelectric power study of non-isothermal precipitation in commercial (8011) aluminium-iron-silicon alloys," Zeitschrift fuer Metallkunde, vol. 88, no. 9, pp. 728-732, 1997.

[9] A. Ney José Luiggi, "Characterization by thermoelectric power of a commercial aluminum-lron-silicon alloy (8011) during isothermal precipitation," Metallurgical and Materials Transactions A, vol. 29, no. 11, pp. 2669-2677, 1998.

[10] E. P. R. Lima, Estudo da cinética de recristalização da liga da aluminio AA8011 na condição H18 [M.S. thesis], Universidade Federal de Pernambuco-Brasil, 2002.

[11] S. Komatsu, M. Ikeda, T. Muramatsu, and M. Matsuo, "Estimation of solute Fe concentration in commercial pure aluminum," in International Workshop on the Effect of Iron and Silicon in Aluminium and Its Alloys, pp. 31-55, May 1989.

[12] C. Garcia-Cordovilla and E. Louis, "A differential scanning calorimetry study of recrystallization and its interaction with precipitation in Al-Fe-Si commercial alloys (AA1145 and AA8011)," Journal of Materials Science, vol. 21, no. 3, pp. 971-979, 1986.

[13] N. J. Luiggi A., "A preliminary study of the phase transformations in rolled Al-Fe-Si alloy," Metallurgical and Materials Transactions A, vol. 41, no. 13, pp. 3271-3275, 2010.

[14] R. Borrelly and J. L. Bouvier-Volaille, "Appareil de caractérisation des alliages par mesure de leur pouvoir thermoélectrique," Traitements Thermiques, vol. 221, pp. 43-45, 1988.

[15] F. J. Blatt, P. A. Schroeder, C. L. Foiles, and D. Greig:, Thermoelectric Power of Metals, Plenum press, New York, NY, USA, 1976.

[16] M. Perez, V. Massardier, and X. Kleber, “Thermoelectric power applied to metallurgy: principle and recent applications," International Journal of Materials Research, vol. 100, no. 10, pp. 1461$1465,2009$.

[17] N. J. Luiggi, "Isothermal precipitation of commercial 3003 AI alloys studied by thermoelectric power," Metallurgical and Materials Transactions B, vol. 28, no. 1, pp. 125-133, 1997.

[18] R. Borrelly, P. Merle, and D. Adenis, "Seebeck effect study of precipitation in 3004," in Proceedings of the Technical Sessions by the TMS Light Metals Committee at the 118 TMS Annual Meeting, pp. 703-712, March 1989. 
[19] R. J. Willson, "Calorimetry," in Principles of Thermal Analysis and Calorimetry, P. J. Haines, Ed., pp. 129-161, Oakland Analytical Services, Farnhurn, Surrey, UK, 2002.

[20] L. He, H. Zhang, and J. Cui, "Effects of pre-ageing treatment on subsequent artificial ageing characteristics of an Al-1.01Mg$0.68 \mathrm{Si}-1.78 \mathrm{Cu}$ alloy," Journal of Materials Science and Technology, vol. 26, no. 2, pp. 141-145, 2010.

[21] C. Y. Yu, P. L. Sun, P. W. Kao, and C. P. Chang, "Evolution of microstructure during annealing of a severely deformed aluminum," Materials Science and Engineering A, vol. 366, no. 2, pp. 310-317, 2004.

[22] N. Luiggi, M. Valera, J. Prin, and M. Linares, "Estudio de la Aleación AA8011 Laminada usando DSC y MET," Acta Microscópica, vol. 22, no. 1, pp. 105-110, 2013.

[23] R. Bisbal, T. Torres, S. Camero, and C. Llanos, "Evolución Microestructural de la Aleación de Aluminio AA8011 Sometida a Tratamientos Térmicos," Acta Microscópica, vol. 18, pp. 179181, 2009.

[24] T. Torres, R. Bisbal, S. Camero, and C. Llanos, "Estudio del Efecto del Tratamiento Térmico de Homogeneización en la Microestructura y Propiedades Mecánicas de una Aleación de Aluminio AA8011," Acta Microscópica, vol. 20, no. 2, pp. 165-173, 2011. 

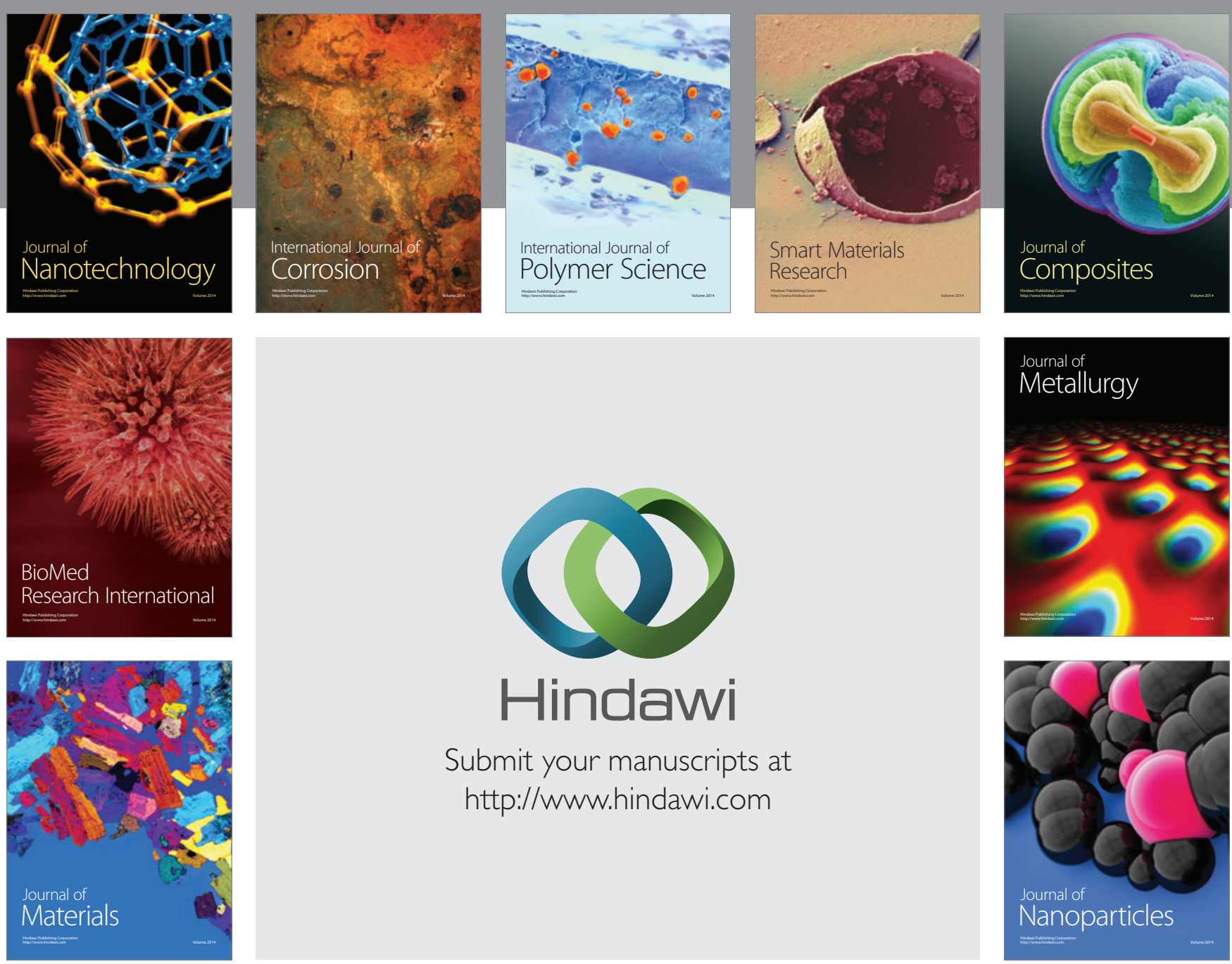

Submit your manuscripts at http://www.hindawi.com
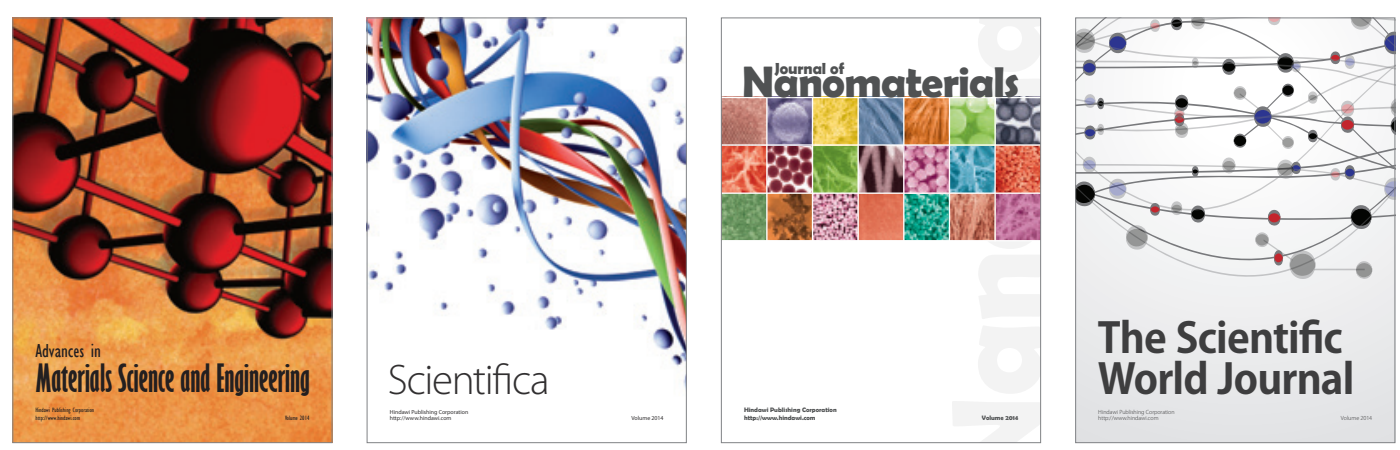

\section{The Scientific World Journal}
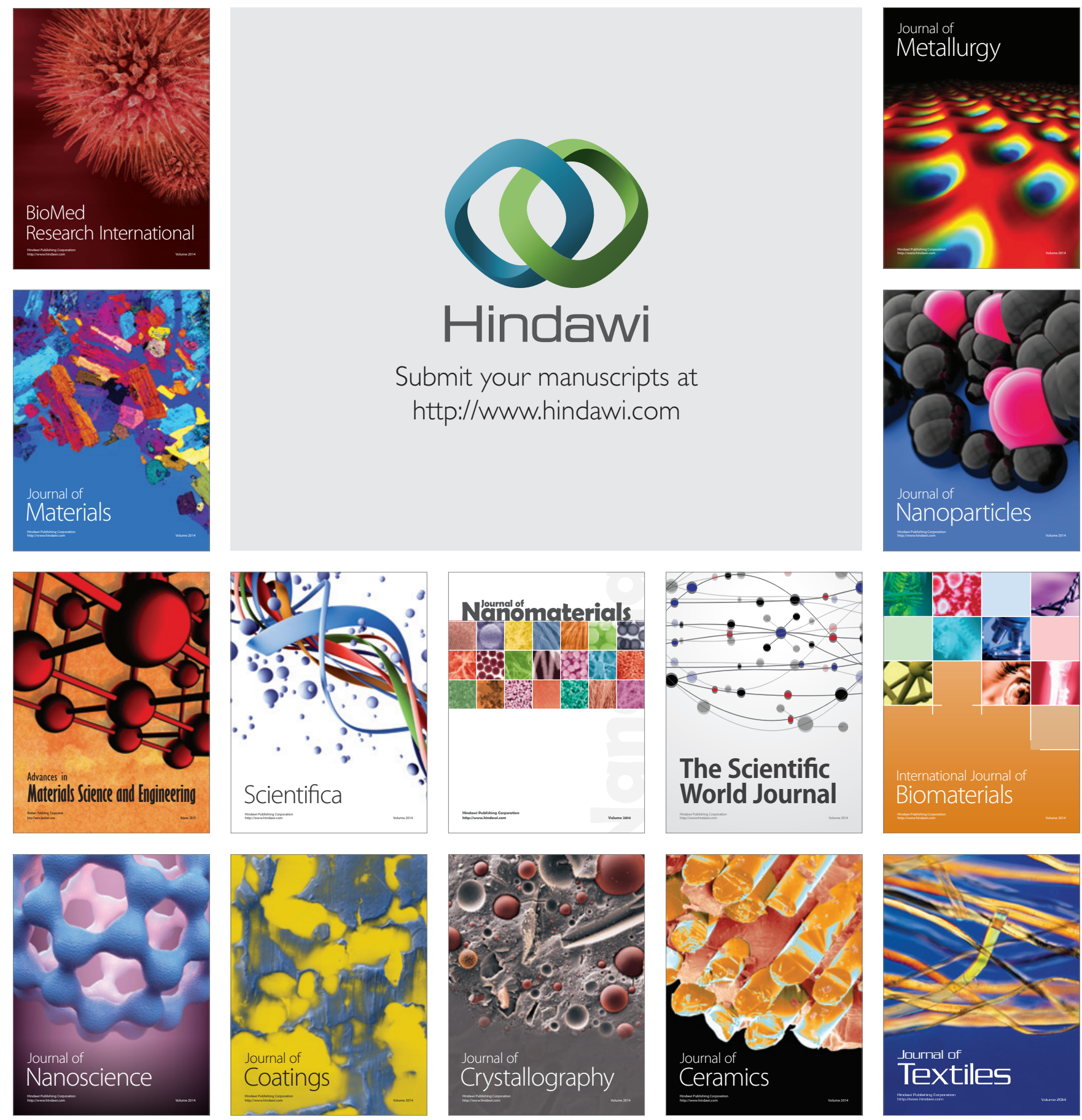